\title{
Radiological Changes in Bones of the Limbs in Leprosy
}

\author{
Mrs. S. KARAT, M.B.B.s., F.R.c.s. (EDIN.) \\ Consultant Surgeon
}

\begin{abstract}
A. B. A. KARAT, B.sc., M.B.B.S., M.R.C.P. (LOND.), M.R.C.P. (EDIN.)
Consultant Physicixn

*RAY FOSTER, m.D., F.A.C.S.

Trainee Surgeon
\end{abstract}

Schieffelin Leprosy Research Sanatorium, B.O., Via Katpadi, North Arcot District, South India

The radiological changes in bones of the limbs in leprosy show a variety of lesions. It is often difficult to classify them into definite groups. Widely varying aetiological and pathological factors may be involved in their production. A single aetiological and pathological factor may produce widely dissimilar radiological appearances. The aetiology can be classified under 3 major groups. First, those changes that are directly attributable to the disease process; secondly, those changes that are secondary to paralytic deformities; and thirdly, those that are secondary to anaesthesia of the limbs and consequent trauma. In a single patient all these factors may exist together. One factor may aggravate the deleterious effect of another, as in the case of plantar ulcer under the metatarsal heads which is made worse by claw toes due to posterior tibial paralysis (Fig. $20 a$ to $c$ ).

Various authors have described some of the patterns of involvement such as leprous dactylitis $^{1}$, concentric absorption ${ }^{2}$ and tarsal disintegration $^{3}$. Mœller-Christensen ${ }^{4}$ has described the various bony changes found in the skeletons of leprosy patients, though without directly relating them to clinical conditions.

This paper describes the various radiological appearances of bones in leprosy and attempts to relate these changes to possible aetiological factors.
PRIMARY INVOLVEMENT

Primary involvement of the bone in leprosy may present as generalised osteoporosis or as localised area of destruction.

\section{Generalised Osteoporosis}

Generalised osteoporosis is often found in patients with lepromatous leprosy who have a high bacillary load (Fig. $1 a$ and $b$ ). There is no definite correlation between the clinical appearance of the hands and feet and the osteoporotic changes seen radiologically. For example, lepromatous nodules or swelling of the fingers may not be present. Biopsy from areas of osteoporosis invariably shows lepromatous granuloma. The bone is soft, and a drill biopsy is easily obtained with manual pressure. The phalanges are fragile and may fracture with moderate trauma. Concurrently with the control of the disease and the reduction in the Bacterial Index, the osteoporosis improves.

Generalised osteoporosis may also occur as a transient phenomenon during reactive episodes in both lepromatous and non-lepromatous leprosy. Among non-lepromatous patients, it is more often present when an active lesion overlies the fingers or toes (Fig. $2 a$ and $b$ ), and in these, histopathological examination shows no evidence of a specific lesion due to leprosy.

* Mwami Mission Hospital, P.O. Box 169, Fort Jameson, Zambia, Africa. 


\section{Localised Osteoporosis}

Localised osteoporosis occurs as circumscribed, well-defined, osteolytic lesions in patients with lepromatous leprosy, or in those with near-lepromatous borderline leprosy (Fig. $3 a$ ). Most of the patients with clinically recognisable disease have a high Bacterial Index. Contrary to previous reports, these are not necessarily associated with nodular lesions or gross infiltration of the overlying skin or subcutaneous tissue or swelling of the fingers ${ }^{5}$. The bones involved are very fragile and may fracture with minimal stress, especially when the subarticular osteolytic areas extend into the surrounding bone. Such pathological fractures are common, and result in angular deformities or fore-shortening of the phalanges (Fig. $3 b$ ). However, with effective anti-leprosy therapy, these areas heal with formation of thick, dense trabeculae. Deformities due to bony displacement at the fracture site persist after healing of the fractures.

Localised osteoporosis may also occur in patients with non-lepromatous leprosy in the bones underlying an active localised skin lesion passing through a phase of acute exacerbation (Fig. $5 a$ and $b$ ). Histopathological examination shows no specific lesion in this area. With the resolution of the skin lesion, the radiological appearance of the bone returns to normal.

\section{Periostitis}

Periostitis is often noticed clinically during the phase of reaction, the patient presenting with intractable pain and tenderness over subcutaneously placed bones. The tibial crest is the most common site (Fig. $5 a$ and $b$ ). Occasionally the subcutaneous border of the ulna may be involved. X-ray examination of these bones reveals thickening of the cortex, and histological examination shows lepromatous infiltration of the periosteal layer of the bone.

BONE CHANGES DUE TO SECONDARY CAUSES

The chief cause of secondary bone changes in leprosy is anaesthesia. The pattern of their occurrence and progression is very similar to that found in other 'neuropathic' conditions in which similar patterns of sensory involvement are present. For example, peripheral neuropathy in diabetes mellitus, syringomyelia, familial sensory neuropathy and meningomyelocele associated with spina bifida all present similar radiological patterns. The Charcot type of disintegration of the joints is conspicuous by its rarity. Joint involvement in the anaesthetic limbs of leprosy demonstrable radiographically is almost always associated with adjacent ulceration and subsequent destruction of the joint.

Some of the less common features of bony changes in anaesthetic limbs occurring in the course of acute and chronic inflammation, and the mode of occurrence and pattern of repair of traumatic lesions are worth describing.

Acute inflammation associated with trophic ulceration results in severe osteoporosis (Figs. 6 and $10 \mathrm{~b}$ ). Sometimes the bone seems to disappear, leaving soft tissue unsupported (Fig. $10 \mathrm{c})$. The bones involved are invariably in communication with a sinus from an adjoining trophic ulcer, and small fragments of osteoporotic bone are frequently extruded through the sinus. However, there is usually no periosteal reaction, nor are large dense sequestra found. Destruction is usually more extensive than repair. Osteomyelitis in anaesthetic bones thus usually results in loss of part of the bone or the entire bone.

In the case of concentric absorption, the endostium attempts to lay down bone while the outer layer of bony cortex is uniformly eroded. The total diameter of the shaft is reduced at the expense of the medullary cavity while the thickness of the cortex itself is maintained (Fig. $18 a$ and $b$ ). Often, these bones are very hard and much more difficult to operate on, than normal bones.

Progressive shortening of the phalanges and metatarsals may also be observed over a period of years. Once an osteomyelitis in an anaesthetic limb heals, destruction of bone does not recur in the absence of another episode of infection. Recurrent infections can arise either as a direct extension of trophic ulceration or as a primary osteomyelitis following a penetrating 
injury or a deep avascular pressure necrosis. The prevention of such infection and injury will obviate further loss of bony substance.

The importance of the relation of the soft tissue to the bony architecture is of ten not fully recognised. Deformities may occur because of muscle imbalance following paralysis, or because of destruction of flexor or extensor tendons at sites of trophic ulceration. These deformities result in abnormal sites of stress, which in turn lead to trophic ulceration and destruction of soft tissue and underlying bone.

On the other hand, loss of supporting bony structure results in contraction of the soft tissues. The soft tissue of the finger may thus be contracted to a third of its original length, with loss of the bony phalanges. The nail and pulp lie at the level of the proximal phalanx, and there is no redundant soft tissue to indicate its original length. The same sequence occurs in the dorsal skin and soft tissues of the feet. Total loss of metatarsals and the adjoining phalanges may result in the remnant of the toes being withdrawn proximally to the level of the tarsals. Ulceration on the plantar surface may account, in part, for the shortening of the plantar soft tissues, but the dorsal skin and subcutaneous tissue (which, as a rule, is not involved in the ulcerative process) is reduced to half its original length without having undergone any obvious destructive process. It is this tendency of the soft tissue to contract in the absence of bony support which has given an air of mystery to the process of shortening of the limbs in leprosy.

On the other hand, loss of support to the soft tissues may result in gross distortion and deformity of the foot (Fig. $18 \mathrm{c}$ ). Stretching or even rupture of the soft tissues by abnormal stress may proceed uninhibited in the absence of pain. The same is true of fractures, which may occur from repeated and unappreciated microtraumata to anaesthetic bones (Figs. 21 to 26). For example, the posterior tuberosity of the calcaneum undergoes avulsion fracture from the pull of the tendo Achillis (Fig. $16 a$ ). This is not an uncommon finding in radiographs of anaesthetic feet. The majority of patients are unaware of having sustained such an injury.

PATTERNS OF BONY CHANGES IN THE LIMBS DUE TO INFECTION

Infection in the anaesthetic limbs includes trophic ulceration initiated by injury, infection or deep aseptic necrosis.

\section{Infection in the hand}

Severe osteolytic lesions due to acute inflammation are common in the fingers (Fig. 6). Recurrences are directly related to the number of injuries sustained. The site of the lesion is determined by the site of injury and has no fixed pattern. However, occupational injuries occur at specific sites due to pressure from unadapted tools. Shortening of the soft tissues follows the destruction in the bony support.

Progressive shortening of the fingers is due to recurrent ulceration and macroscopic and microscopic sequestration of bone (Fig. 8 a to $d$ ). Pathological fractures of the diseased bone contribute both to the shortening and to the angular deformities of the fingers (Fig. 7).

\section{Infections of the foot}

The basic pathology of the progress of infection in the foot is similar to that of the hand (Fig. $10 a$ to $c$ ), but the distribution of plantar ulcers follows a definite pattern. In a foot that is not distorted and which retains the normal mechanics of gait, ulcers occur along the areas of maximum stress which corresponds to the walking roll ${ }^{6}$. However, when the areas of stress are altered during walking, owing either to muscle imbalance or to destruction of the bony support, the areas of trophic ulceration are correspondingly altered.

The radiological appearance of bone changes due to plantar ulceration has no consistent pattern (Fig. 9). Uniform concentric absorption, or irregular absorption, or widely varying distortions following irregular loss of bone and joints, gives a bizarre appearance, that may defy description (Figs. 9 and 19 b). Individual bones may be dense and sclerotic, or they may show severe osteoporosis or osteolysis. The joints may 
become arthritic, or develop fibrous ankylosis or bony union. Often, the adjoining bony components of a joint are destroyed, leaving a large gap between the two ends. Soon the soft tissue contracts and pulls the bony ends together (Figs. $11 c$ and $17 b$ and $c$ ). Such distortion is often associated with destruction of some of the tendons acting on the joint. The resulting imbalance of muscle action produces a postural deformity of the part, distal to the joint. Thus, destruction of the flexor tendons under the metatarsal heads results in unopposed hyperextension, and dorsal and proximal subluxation of the toes is commonly found following deep plantar ulceration (Fig. $20 \mathrm{c}$ ).

PATTERNS OF DESTRUCTION DUE TO PLANTAR ULCERATION

\section{Individual bones or toes}

Fig. $10 a$ to $c$ shows a series of radiographs from different patients, that demonstrate the pattern of progressive destruction of a toe until it is totally lost. This may occur rather rapidly during an acute episode, followed by chronic ulceration if the patient remains untreated, or it may take many years of recurrent ulceration. Each such episode results in a small amount of bony destruction. The foot that has lost its big toe develops new areas of stress. Such an area may be the distal end of the first metatarsal head, unprotected by the big toe, and overlying a scarred avascular area, or it may be the adjoining toes, which deviate without the support of the hallux (Fig. $10 c$ ), or it may be another metatarsal head which has come to bear the maximum stress during the 'kick-off phase' of walking. Footprints show the changing pattern of stress. Without protective footwear, these new areas of stress are likely to become the seat of plantar ulcers.

When loss of bony support is more extensive than is represented by a single toe, the remaining part of the foot suffers a marked reduction in the total weight-bearing surface, and consequently shows a greater predilection to trophic ulceration. In such cases, the outlook for long-term trouble-free survival of an active anaesthetic foot is poor. When such destruction involves the major components of the foot, the resulting functional imbalance during weight-bearing aggravates the tendency to plantar ulceration in the new areas of stress.

The major components of the foot are the medial ray, the lateral ray, forefoot and hind foot.

\section{Medial Ray}

The highest incidence of plantar ulcer occurs on the medial side of the forefoot: $27 \%$ of all plantar ulcers occur under the big toe and the first metatarsal head ${ }^{6}$. Recurrent ulceration results in the destruction of the big toe and the first metatarsal head (Fig. $11 a$ to $c$ ). The forefoot loses a third of its weight-bearing surface, and this results in excessive pressure under the adjoining metatarsal heads.

\section{Lateral Ray}

The incidence of plantar ulceration under the fifth metatarsal head is $15 \%$, but in cases of lateral popliteal paralysis the fifth metatarsal head shows peak pressure at the onset of the 'stance' phase, when the foot hits the ground in a slightly inverted and plantar-flexed position. Thus, lateral ray destruction is common in lateral popliteal paralysis (Fig. $12 a$ and $b$ ).

\section{Forefoot Ulceration}

Ulceration and destruction of the metatarsal heads in the forefoot is commonly seen. As already pointed out, loss of one metatarsal head predisposes to ulceration in the skin overlying the remaining metatarsals. Footdrop, tendo Achillis contracture, or equinus deformity due to any other cause aggravates the tendency for forefoot destruction. Fig. $14 a$ to $d$, a series of radiographs from different patients, show progressive shortening of the forefoot. The final result is severe reduction in the weight-bearing area.

\section{Hind Foot}

Heel ulcers are often chronic. Once the calcaneum is involved, osteomyelitis extends deep into the bone meeting with very little resistance, and the shell of the calcaneal cortex 
becomes fragile and vulnerable to trauma. Avulsion of the posterior tuberosity by the pull of the tendo Achillis or fracture of the calcaneum itself is a common occurrence. (Fig. $15 a$ to $c$ and Fig. $16 a$ and $b$ ). The posterior fragment of the calcaneum is pulled backwards by the tendo Achillis, and as the ulcer heals the calcaneum assumes the shape of an elongated boat (Fig. 16 b).

The infection in the soft tissue may spread anteriorly to involve the calcaneo-cuboid and calcaneo-navicular joints. Once these joints are destroyed, the head of talus is in direct contact with the plantar ulcer and soon becomes involved. The process of mid-foot destruction is thus initiated.

THE IMPORTANCE OF MAINTAINING THE ARCHITECTURAL INTEGRITY OF THE FOOT

A balanced foot, in which the bones support each other and the mechanics of weight-bearing follow a normal pattern, is considered necessary if the anaesthetic foot is to maintain its integrity. Fig. $17 a$ to $c$ illustrate the need for maintaining architectural integrity, so that balanced distribution of pressure in the foot may not be altered. Fig. 18 a to $c$ illustrate the severe disintegration that may result from destruction of the soft tissue components that help to maintain the normal alignment of the bones of the foot.

\section{PARALYTIC DEFORMITIES}

Paralytic deformities may result in fixed deformities and secondary bony changes (Fig. 19).

Abnormal position of bones and joints, combined with imbalance of the muscle action on the joint, may result in alterations in the distribution of pressure in the foot. Ulcers over the metatarsal heads occur as a result of abnormal pressures from claw toes (which are themselves the result of paralysis) (Fig. 20 $a$ to $c$ ), and from lateral ray destruction from lateral popliteal paralysis.

FRACTURE IN ANAESTHETIC BONES (FIG. 21 TO 26)

Fractures in anaesthetic feet are often unrecognised by the clinician. These fractures occur most commonly as a result of unappreciated repeated micro-traumata and are similar to march fractures in their causation ${ }^{3}$. Osteoporosis, abnormal posture of the foot while walking, and infection are the common predisposing factors?

\section{Osteoporosis}

Osteoporosis may be due to prolonged immobilisation (Figs. $21 a$ to $b, 23,24 a$ and $b$ and 25), or it may be due to long-continued steroid therapy (Fig. 22). Sometimes it is due to primary lepromatous granuloma in the bones (Fig. $3 b$ ).

\section{Abnormal posture of the foot}

The common clinical example is walking on a dorsiflexed foot. A tight 'foot-drop spring', or a foot immobilised in a walking cast with the ankle held at extreme dorsiflexion, are common causes of such abnormal postures (Figs. 23 and 14). The trabeculae of the bone are normally arranged according to the lines of stress, along which the body weight is transmitted. When the foot is held in dorsiflexion and the patient is made to walk, the line of transmission of body weight is altered. This results in fractures along the line of maximum stress.

\section{Infection}

Bony destruction due to osteomyelitis is a common cause of fractures in anaesthetic limbs. The bones may be so fragile that minimal force produces a fracture (Fig. 26).

\section{SUMMARY}

An illustrated outline of radiological changes observed in the limbs of leprosy patients is presented. These are broadly classified as primary and secondary changes. Primary changes are seen in patients with either lepromatous or non-lepromatous leprosy. Secondary changes, the result of anaesthesia and/or paralysis, are outlined. Changes in individual bones due to trophic ulceration, as well as general patterns of destruction due to plantar ulcers in the foot, are described. The effect of paralytic deformities in anaesthetic limbs is 
pointed out. The need for maintaining architectural integrity of the foot is emphasised, and illustrated with examples. Fractures and their aetiology in anaesthetic limbs are outlined and illustrated. An attempt is made to correlate radiological changes with the clinical course.

\section{ACKNOWLEDGEMENTS}

It is a pleasure to acknowledge the secretarial assistance rendered by Miss M. Indira. We are thankful to Mr. S. D. Sigamani for his valuable help with the photographs, and to Mr. M. A. Furness for assistance with the manuscript.

We are grateful to The Leprosy Mission and the American Leprosy Missions Inc. for continued support and encouragement.

\section{REFERENCES}

1. PAterson, D. E. and Јов, C. K. (1963). Bone changes and absorption in leprosy. Leprosy in Theory and Practice. 2nd Ed., John Wright \& Sons of Bristol, 1964, pp. 425-446.

2. Paterson, D. E. (1961). Bone changes in leprosy, their incidence, progress, prevention and arrest. Int. J. Lepr., 29, 393.

3. harris, J. R. and BRAND, P. W. Pattern of disintegration of the tarsus in the anaesthetic foot. J. Bone.Joint Surg., 48-B.

4. meller-christensen, v. (1961). Bone changes in leprosy. Copenhagen, Munksgaard.

5. KARAT, s. Personal observation.

6. PRICE, E. W. (1959). Studies of plantar ulcers in leprosy. Lep. Rev., 30, 98.

7. Karat, s. Mode of occurrence and healing of fractures in anaesthetic limbs in leprosy. Paper read at The International Seminar on Leprosy, Agra, January 31-February 3, 1967. 


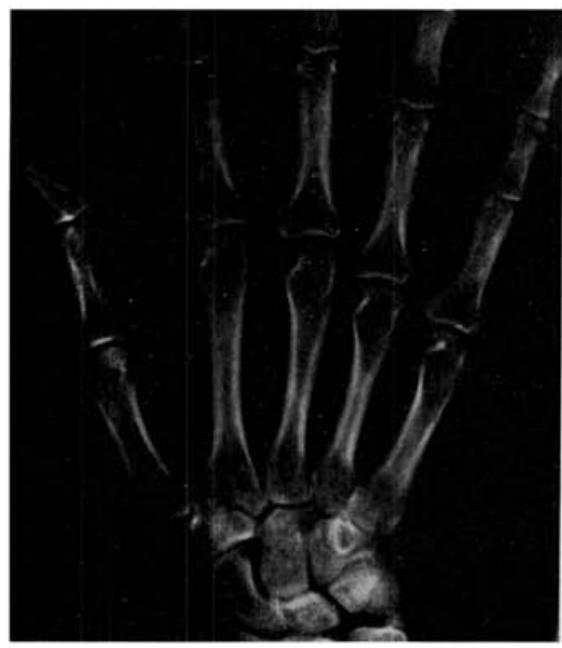

FIG. I (a)

Fig. $1(a)$ and $(b)$

Case History: Name: N.R. Age: 35. Sex: Male. SLRS No. 7973. X No. 4289. Lepromatous leprosy of 7 years' duration. Was admitted with infiltrated lesions over the face and back. Fingers were swollen and spindle. shaped, but not tender.

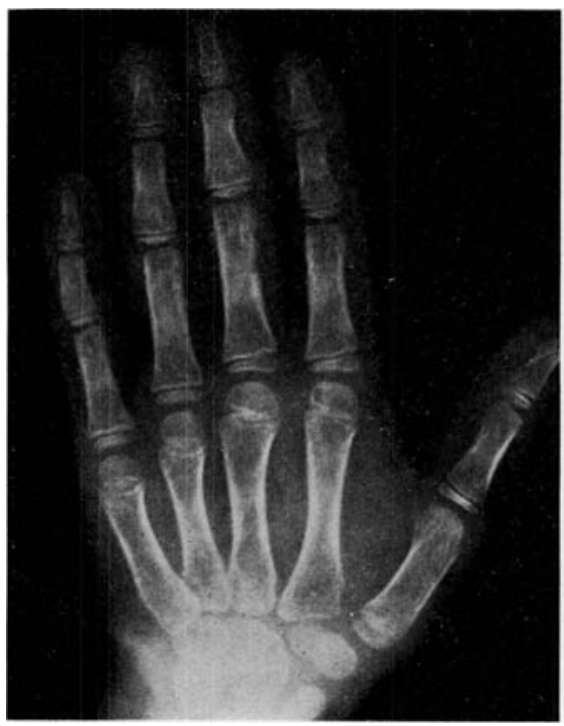

FIG. 2 $(a)$

FIG. $2(a)$ and $(b)$

Case History: Name: A.R. Age: 9. Sex: Male. H. No. 8077. X. No. 2571. Admitted with a history of multiple patches over the body of 1 year's duration.

On examination: A number of well-defined, hypopigmented infiltrated lesions with raised edges and resolving centres, most of which are anaesthetic. There was a lesion over the left middle finger with fusiform swelling of the entire finger and pebbling along the edges, with satellite lesions. X-ray showed osteoporosis of the phalanges. Skin smear for acid-fast bacilli was negative. Skin biopsy taken on 3 l. III.1966 from a patch on the left leg showed typical tuberculoid

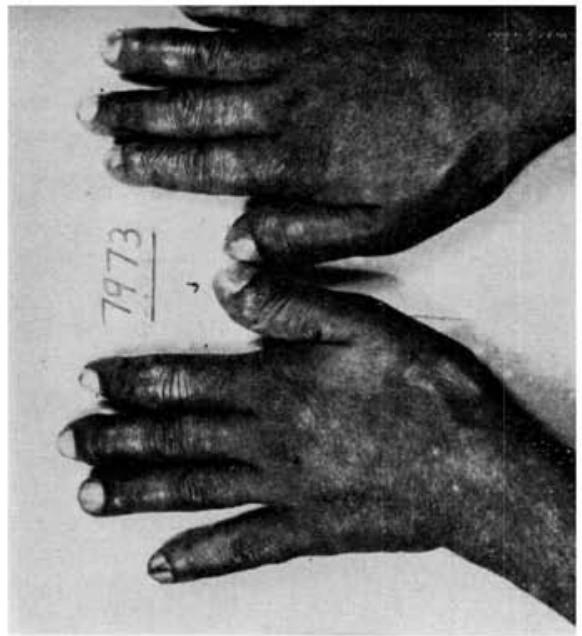

FIG. I $(b)$

X-ray: X-ray taken on 3l.VI.1966 shows marked sub-articular osteoporosis of all the phalanges with severe osteolysis of the adjoining surfaces of the proximal inter-phalangeal joint of the index finger. Biopsy taken on 15.IV.1966, from the left little finger, head of the middle phalanx, shows lepromatous granuloma of the bone.

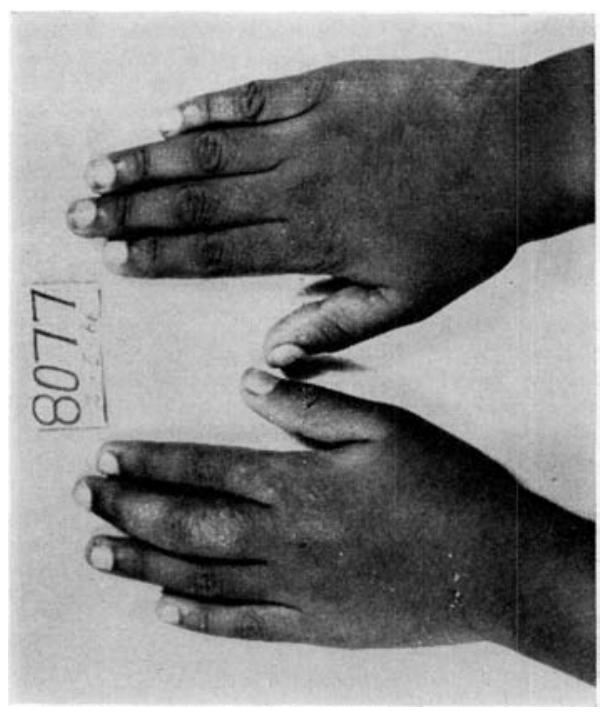

FIG. $2(b)$

leprosy. Bone biopsy was taken from the proximal phalanx of the middle finger on 25.III.1966. Histology showed bone and fibrous tissue with no evidence of inflammation due to leprosy.

$X$-ray: X-ray shows generalised osteoporosis. Patient was treated with steroid and anti-leprosy drugs. $\mathrm{X}$-ray taken 3 months later showed no osteoporosis. The swelling and erythema in the finger subsided, and the patient had no further symptoms.

Summary: Generalised osteoporosis of bones of hand under a tuberculoid leprosy patch. Negative skin smears; bone biopsy-negative. 


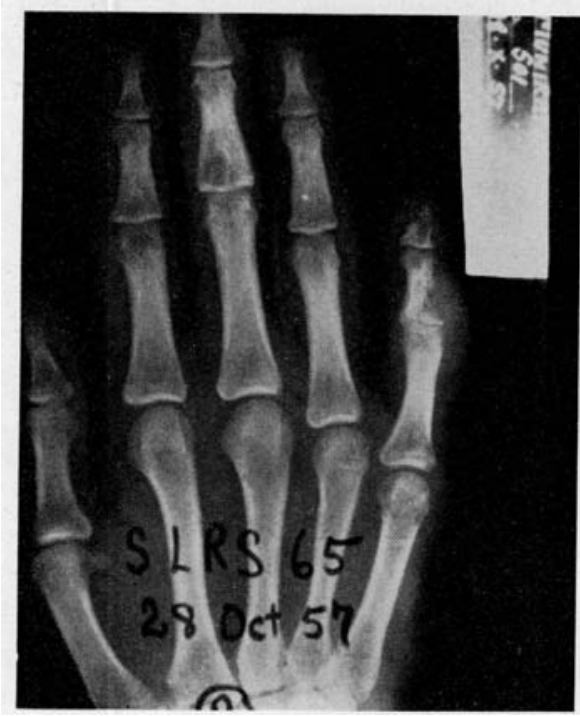

FIG. $3(a)$

FIG. $3(a)$ to $(c)$

Case History: Name: M.R. Age: 30. Sex: Male. H. No. 501 . X. No. 65. Lepromatous leprosy of 12 years' duration, with history of repeated reaction; treatment with anti-leprosy drugs for one year, with repeated interruptions due to reactionary episodes. Ulcerative nodules all over the extremeties and buttocks. Right hand showed diffuse swelling of all the phalanges, slightly more around the proximal interphalangeal joints of index, long and little fingers. Nodules over the dorsum of the hand with ulceration. No gross deformity at that time.

FIG. $3(a)$

X-ray taken 28.X.1957, showed osteolytic lesions, fairly localised, at the base of the middle phalanx of the index finger, head of the proximal phalanx of the index finger, terminal tufts of index, long and little fingers, base of the middle phalanx of the middle finger and base and lateral surface of the middle phalanx of of the little finger with soft tissue shadow around it. Biopsy taken from the index finger proximal phalanx on 12.XI.1957, showed dense inflammation, mainly foamy cells and macrophages, with small islands of dead bone. Acid stain for acid-fast bacilli shows cells loaded with leprosy bacilli.

$$
\text { FIG. } 3(b)
$$

X-ray dated 28.I.1958, after one year anti-leprosy treatment, bacillary index 2.6. Patient had no reaction in this interval. $\mathrm{X}$-ray shows more definite osteolytic areas in all the fingers, and more osteolytic changes in the tufts of all the fingers. In addition, there is a subarticular fracture at the head of the middle phalanx of the ring finger with ulnar angulation of the distal fragment.

$$
\text { FIG. } 3(c)
$$

$\mathrm{X}$-ray dated 5.VIII.1960. Patient has had 3 more years of treatment, interrupted repeatedly because of recurrent reactions. Smear taken 30.XII.1960 showed bacterial index of 2.12. Skin biopsy done 22.II.1963 shows typical lepromatous leprosy. X-ray now shows

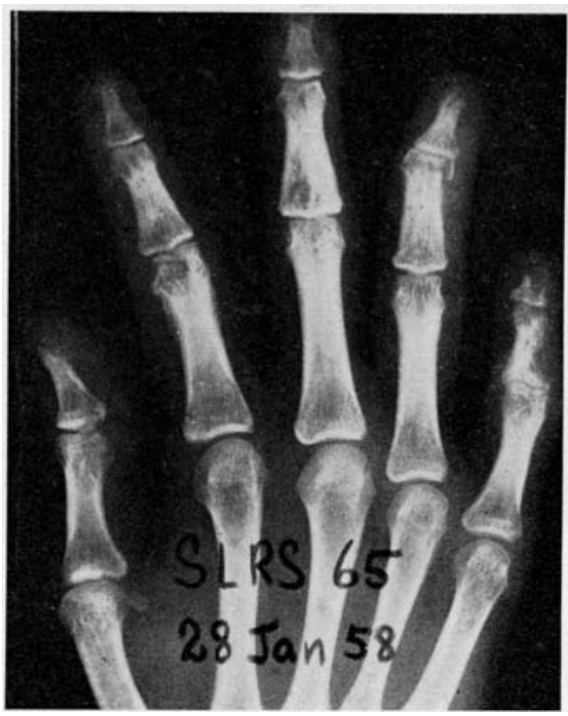

FIG. $3(b)$

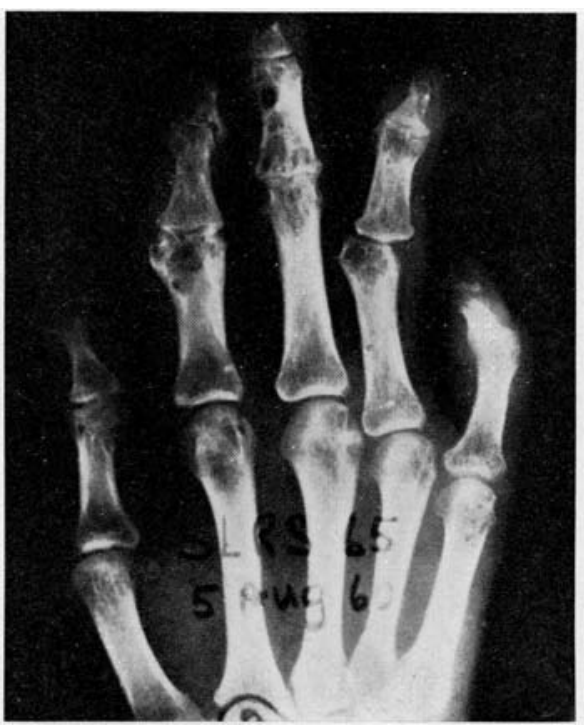

FIG. $3(c)$

increase in the size of sub-articular osteolytic areas with some broadening of the proximal phalanx of the middle finger. The fracture at the distal sub-articular area of the middle phalanx of the ring finger (seen in the earlier X-ray) has healed with good continuous trabeculae formation. Angular deformities of proximal interphalangeal joint of ring and little fingers are seen. Some early changes in the head of the index finger metacarpal is present.

Summary: Hand X-ray shows localised areas of lysis of bone showing early changes, moderate changes 3 months later and marked changes 33 months later. Bone biopsy shows lepromatous granuloma.

\section{4




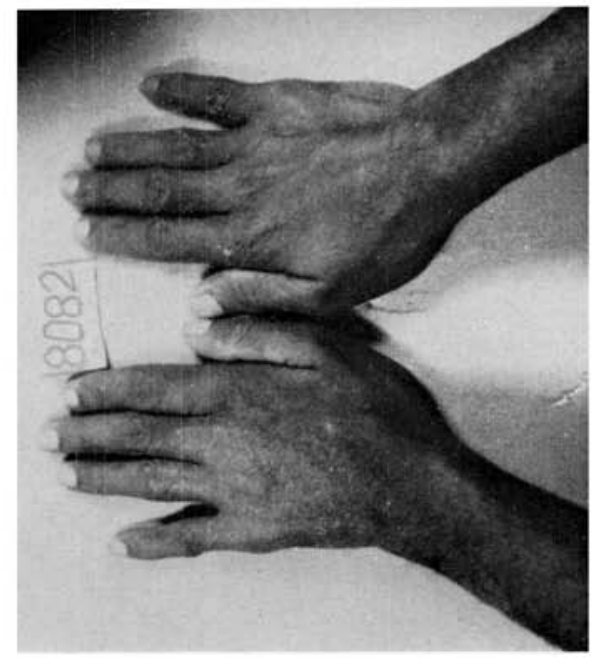

Fig. $4(a)$

Case History: Name: M. Age: 29. Sex: Male. H. No. 8082. X. No. 252. Diagnosis: Tuberculoid leprosy. 30.III.1966, patient gave a history of hypopigmented patches over the forehead and limbs of 8 months' duration, and exacerbation of these lesions for 2 months. On examination: There were large numbers of welldefined infiltrated hypopigmented lesions with clear-cut edges, a number of them showing central resolution. Large plaque-like lesions over the left hand, with maximum infiltration in the centre. Infiltrated erythematous left ear and enlarged greater auricular nerve were present. There was considerable oedema of both lower limbs, but no swelling of the hands. Skin biopsy from the left shoulder and left forearm showed typical tuberculoid leprosy. Lepromin test was positive.

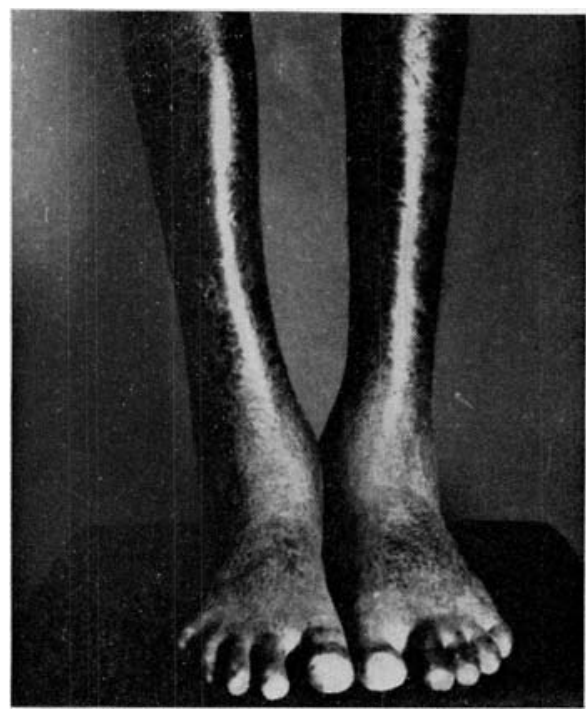

FIG. 5 $(a)$

Case History: Name V.N. Age: 17. SLRS No. 4455. X. No. 683. Lepromatous leprosy. Bacillary index for acid-fast bacilli in the skin smear was 0.62 . Duration of disease: 6 years. Generalised fine lepromatous infiltration of trunks and limbs, and nodular infiltration of face, ears and eyebrows. History of repeated reactions, with erythema nodosum leprosum. Swelling

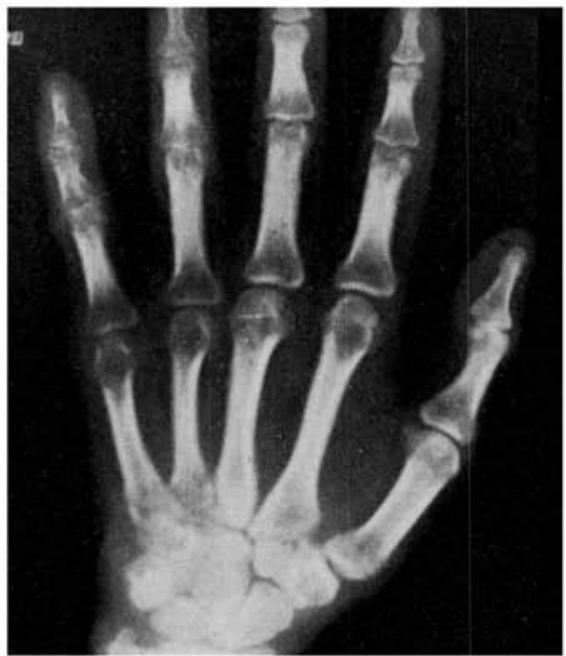

FIG. $4(b)$

Histological section of lepromin test site showed changes characteristic of tuberculoid leprosy. Radial cutaneous nerve biopsy also showed tuberculoid leprosy. Skin smears for acid-fast bacilli were negative.

FIG. $4(b)$

$\mathrm{X}$-ray taken on 30.III.1966 shows sub-articular osteoporosis of all the phalanges of little and ring fingers. Biopsy taken from the base of the middle finger proximal phalanx shows fibrous tissue and bone with no leprosy lesions.

Summary: Localised severe osteoporosis with no significant microscopic lesions in tuberculoid leprosy during a phase of exacerbation.

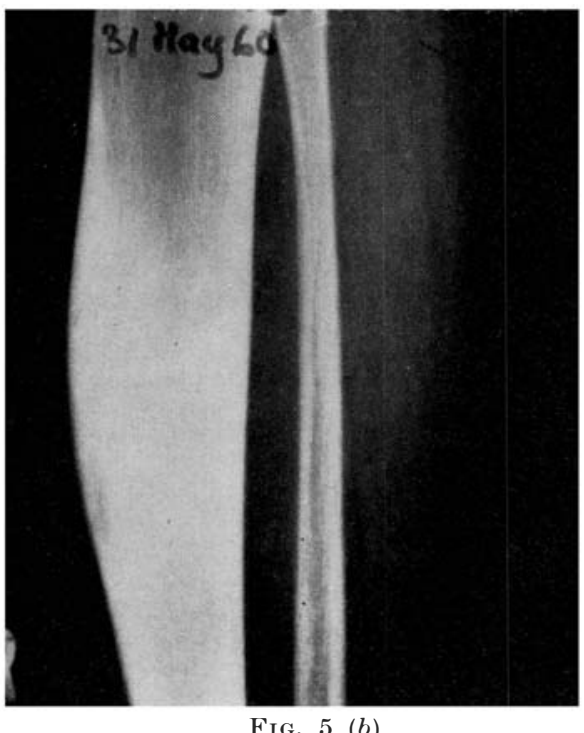

along the tibial crest, with pain and tenderness. Pain worse at night.

FIG. $5(b)$

X-ray No. 683. X-ray taken on 3l.V.1960 shows periostitis. Biopsy taken on 6.VI.1960 shows periostitis, due to lepromatous leprosy. 


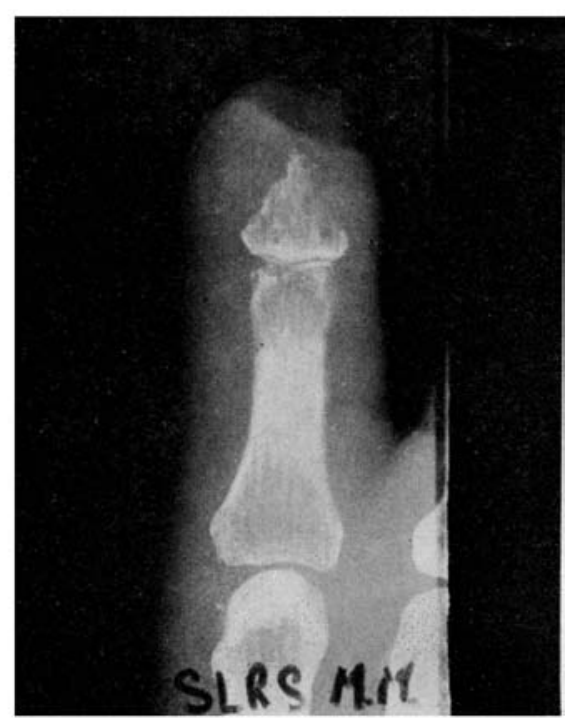

FIG. 7

Example of bony destruction in the hand due to infection and chronic ulceration in anaesthetic fingers, with marked osteolysis, destruction and subluxation at the terminal interphalangeal joint and pathological fracture of the neck of the middle phalanx. There is very little evidence of periosteal reaction in the adjoining bones. Note the soft tissue shortening due to internal derangement and destruction of the architecture of the finger.
FIG. 6

$\mathrm{X}$-ray of bone changes of the adjoining surfaces of the proximal interphalangeal joint of an index finger following injury and infection in an anaesthetic hand with chronic ulceration and bone changes.

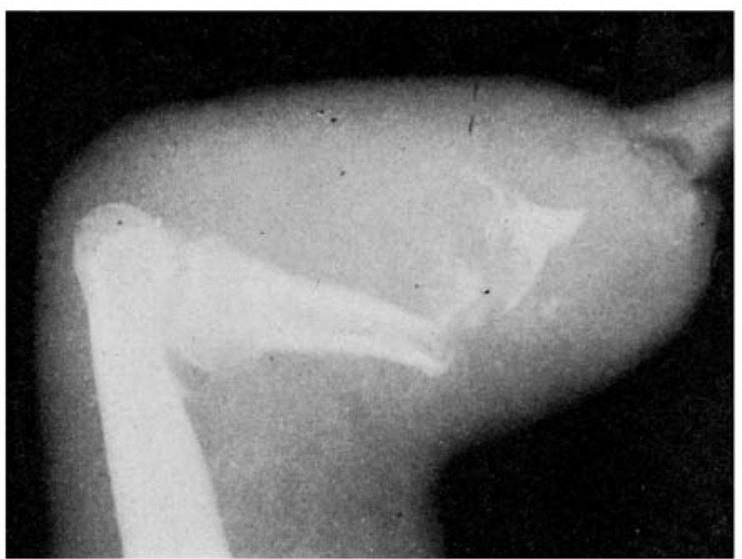




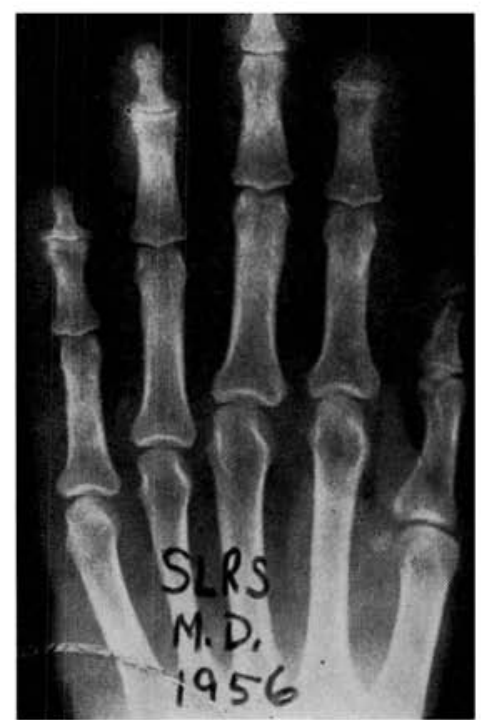

FIG. $8(a)$

FIG. $8(a)$ to $(d)$

Series of X-rays showing the pattern of shortening of the fingers to the level of the metacarpals due to chronic repeated ulceration of the fingers of the anaesthetic hand.

$$
\text { FIG. } 8(a)
$$

$\mathrm{X}$-ray shows various degrees of early destruction of the terminal phalanges of anaesthetic finger due to injury and infection. Thumb shows destruction of the terminal tuft, with a loose piece of bone. Index finger: soft tissues of the terminal phalanx are destroyed and

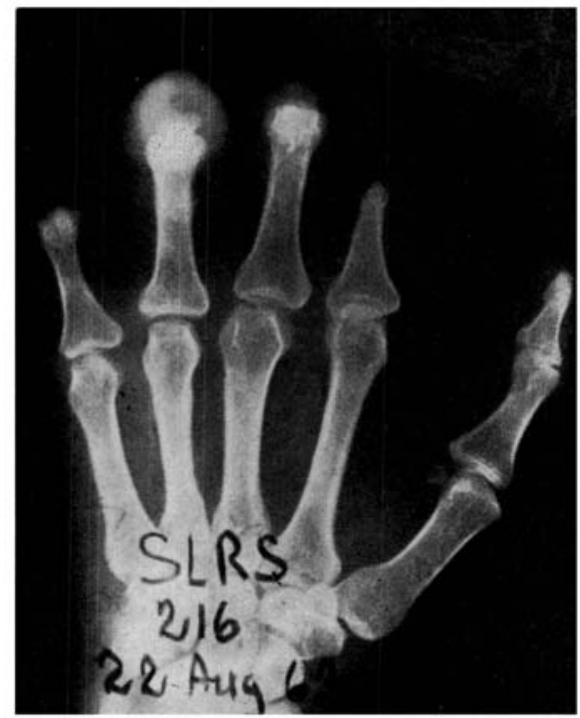

FIG. $8(c)$

Gross destruction of the hand, leaving stumps of proximal phalanges fromindex to little finger. Evidenceof inf ection and sof $t$ tissue swelling in the ring finger stump.

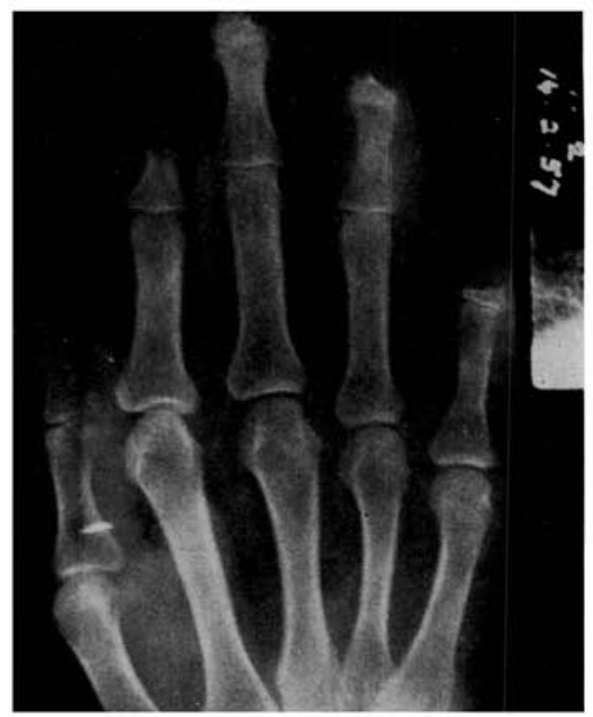

FIG. $8(b)$

shortened up to the level of the base of the terminal phalanx, with the joint line still intact. Note some soft tissue destruction of the radial side of the pulp of the ring finger.

$$
\text { Fig. } 8(b)
$$

More advanced destruction due to recurrent episodes of injury and infection with loss of major part of terminal phalanx of long and ring fingers and destruction up to the base of middle phalanx of index and little fingers. Dense soft tissue shadow and mottling of the ring finger indicates presence of infection and osteomyelitis. Note the absence of periosteal reaction.

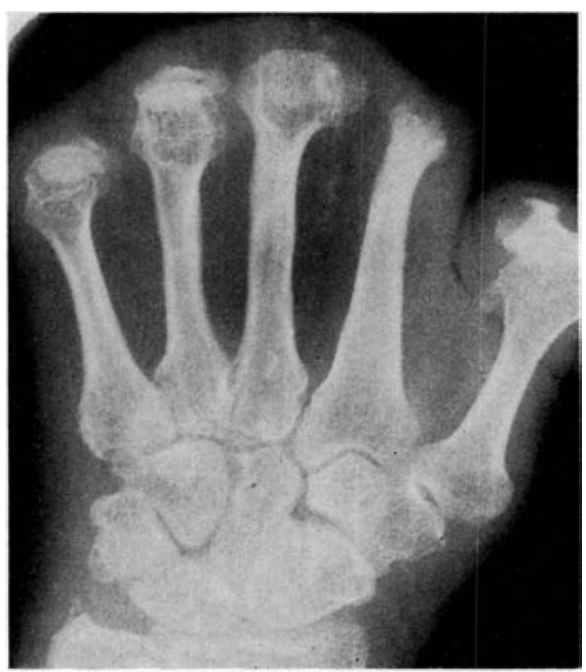

FIG. $8(d)$

Complete destruction of the fingers with only metacarpals and bony remnants of proximal phalanges left. (Corn picker's hand.) 


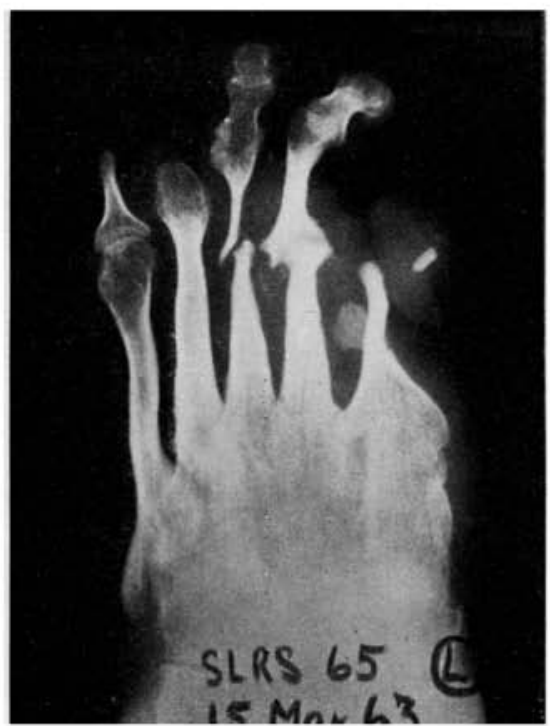

Fic. 9

An example of a foot showing result of trophic ulcerations of all the toes and metatarsal heads resulting in varying patterns of healing in each bone.

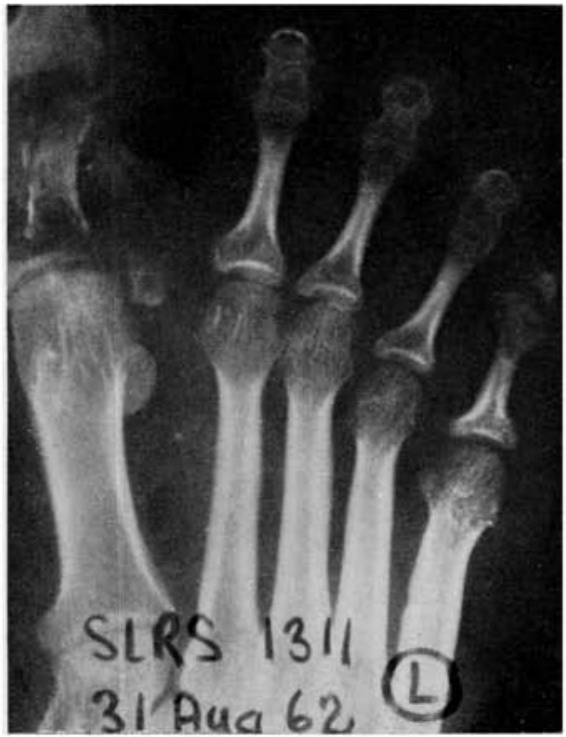

FIG. $10(a)$

FIG. $10(a)$ to $(e)$

Series of $\mathrm{X}$-rays showing pattern of progressive destruction and loss of big toe due to repeated ulceration.

FIG. $10(a)$

Acute inflammation due to 'trophic' ulceration under the interphalangeal joint of big toe with early des-

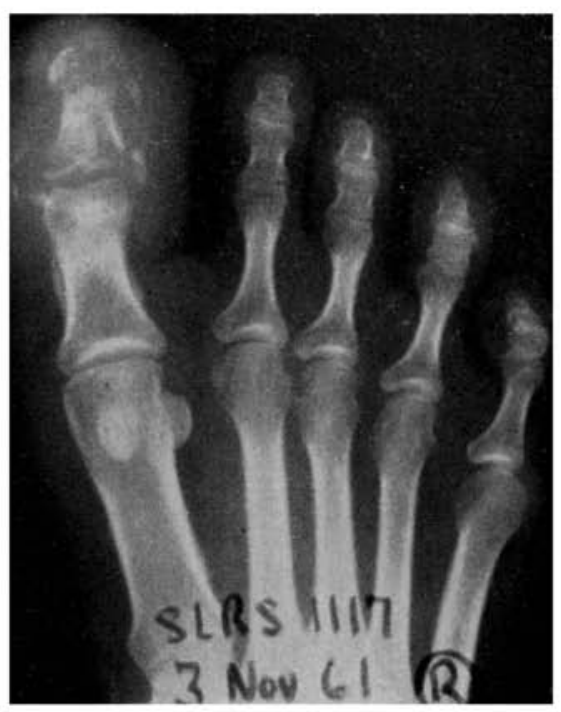

FIG. $10(b)$

truction of the adjoining surfeces of bones of the interphalangeal joints. There is gross soft tissue swelling and some periosteal reaction of the proximal phalanx.

Fig. $10(b)$

Shows further destruction of the bone with more marked destruction of the proximal phalanx and early destruction of the distal phalanx. 


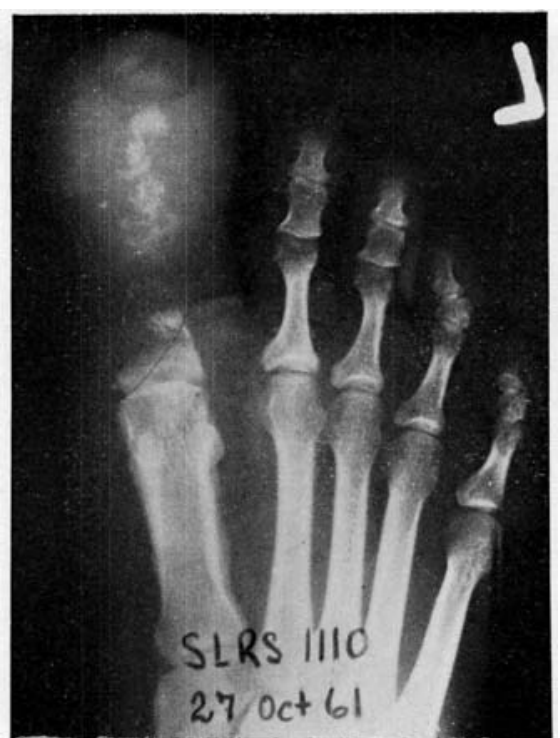

FIG. $10(c)$

Shows gross soft tissue swelling and extreme osteolysis of the proximal phalanx. Remnants of pieces of distal phalanx lying in the soft tissue. There is periosteal reaction along the shaft of the proximal phalanx.

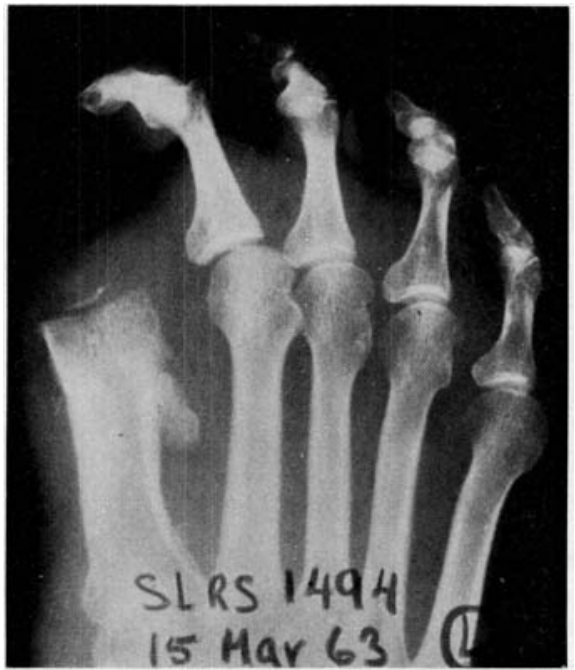

FIG. $10(e)$

Shows disappearance of the entire proximal phalanx, including the base of the big toe, due to repeated chronic ulceration on the distal-medial surface. Early changes in the head of the first metatarsal with some changes of the sesamoid bone. Note the deformity of the second and third toes, inclining towards the area of the big toe in the absence of its support.

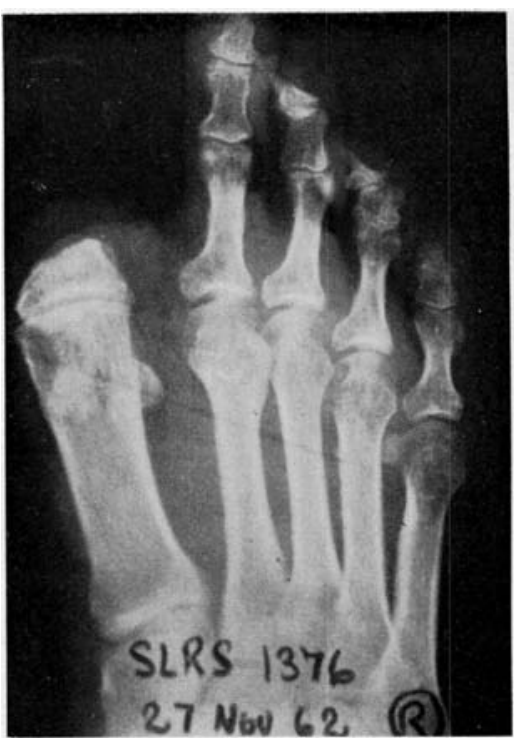

FIG. $10(d)$

Shows destruction of the entire big toe up to the base of proximal phalanx, with complete disappearance of the sof tissue. Some uniform thickening of the proximal phalanx, due to increased weight-bearing on this surface.

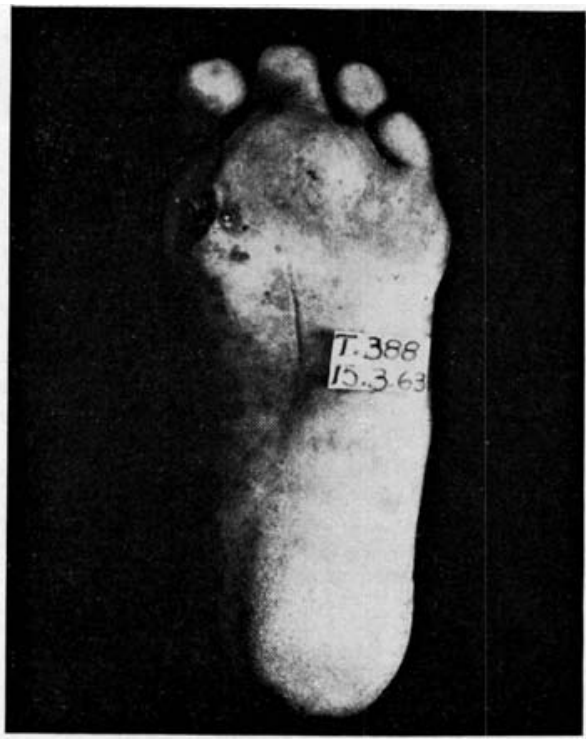

FIG. $10(f)$

Clinical pictures of a foot which has lost its big toe due to progressive destruction following chronic ulceration. 


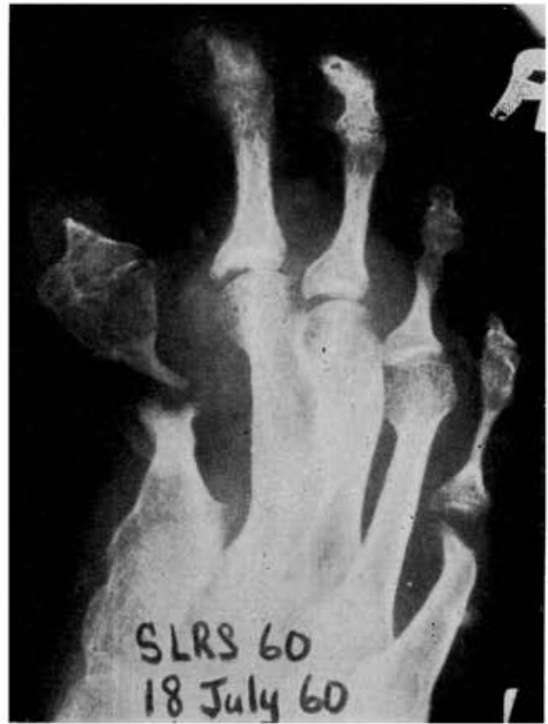

FIG. $1 \mathrm{l}(a)$

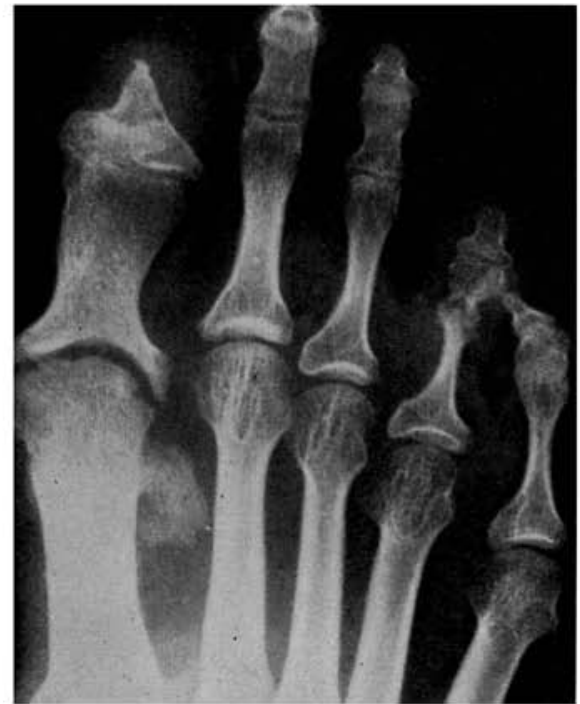

FIG. $11 \quad(b)$

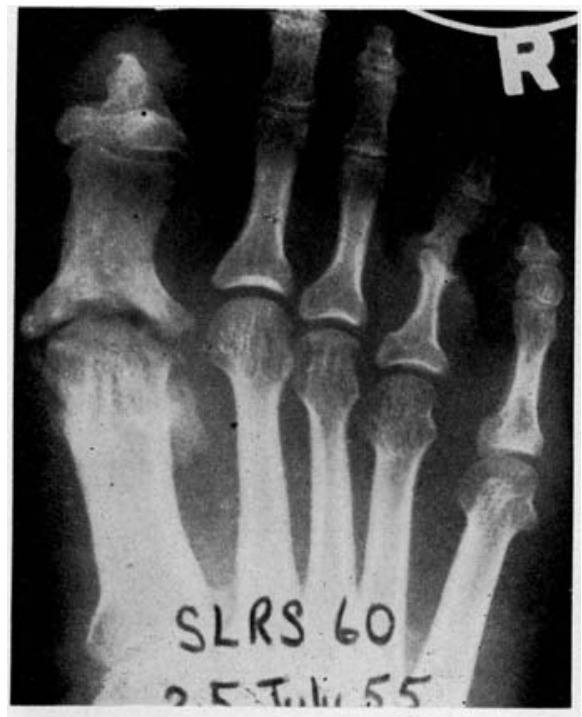

FIG. $11(c)$

FIG. $11(c)$

Five years later, $\mathrm{X}$-ray shows gross shortening of the great toe with destruction of most of the proximal phalanx and first metatarsal head. Note the new ulcer under the fourth and fif th metatarsal heads and under the pulp of the other toes, resulting in early destruction in these areas. 


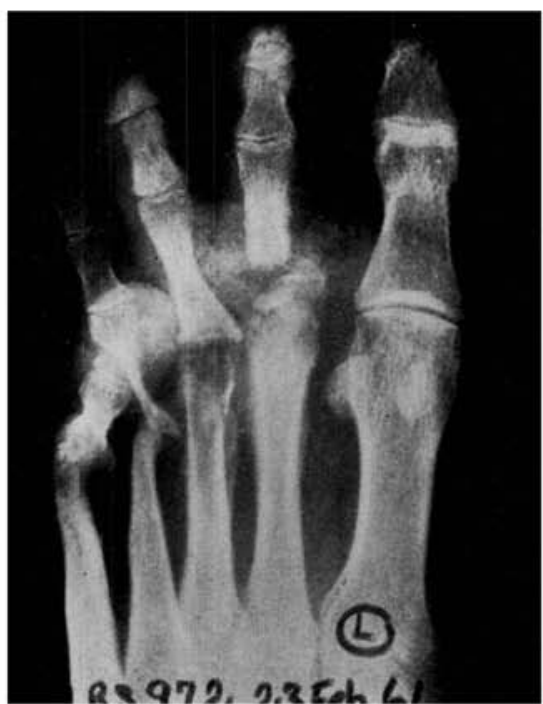

FIG. $12(a)$

FIG. 12 $(a)$ and $(b)$

Case History: Name: M.A. Age: 39. Sex: Male. SLRS No. 5044. X. No. 972. Patient with arrested lepromatous leprosy and negative skin smears. Disease 5 years' duration. Onset with fissures in left sole. Patient was admitted 31.I.1961 with swollen left foot and plantar ulceration over the lateral metatarsal heads which was initially treated with antibiotics, bed rest and elevation and later in plaster immobilisation. These ulcers took 11 months to heal (November, $1961)$. Frequent recurrences during the next 3 years. The second X-ray was taken dated 29.V.1964.

\section{FIG. $12(a)$}

$\mathrm{X}$-ray on 23.II.1961, shows destruction of the second, third, fourth and fifth metatarsal heads, resulting in

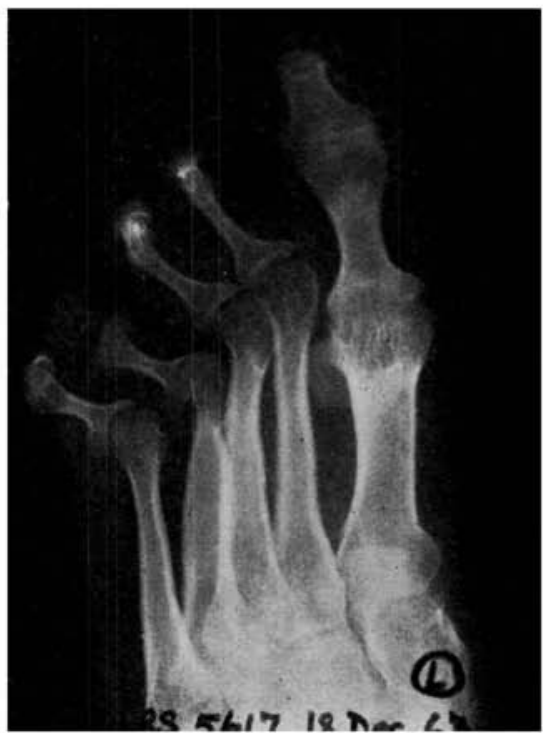

FIG. $13(a)$

$\mathrm{X}$-ray of a patient with ulceration of the metatarsal heads and destruction of the inferior capsule and deformity of the metatarso-phalangeal joint.

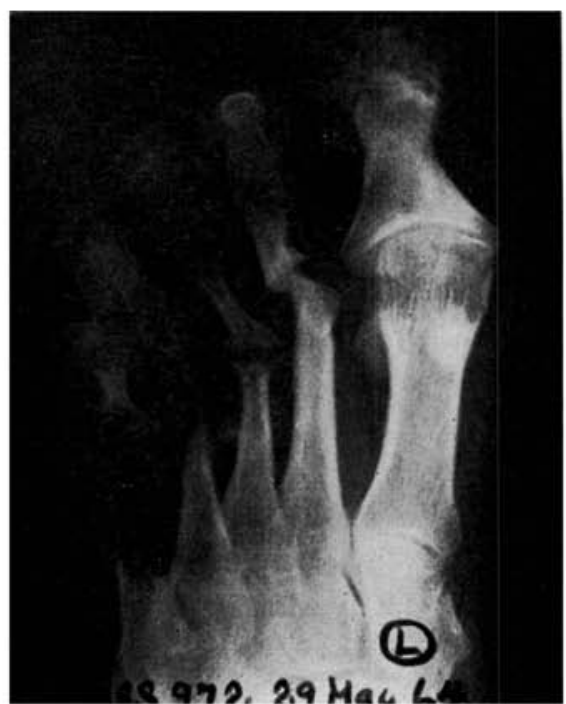

FIG. $12(b)$

loss of alignment of corresponding toes and destruction of metatarso-phalangeal joints.

\section{FIG. $12(b)$}

X-ray taken on 29.V.1964, after a 3-year interval, shows gross shortening of the metatarsals of the lateral foot with shortening of the toes. Note the different patterns of healing after ulceration. At the second metatarso-phalangeal joint level there is fusion. At the third toe there is fibrous ankylosis with deformity. Fourth toe shows extreme concentric absorption with probably fibrous connection between the narrowed metatarsal base and the proximal phalanx. The fifth metatarso-phalangeal joint shows a large gap between the remnants of the fifth toe and the fifth metatarsal with broadening of both the edges.

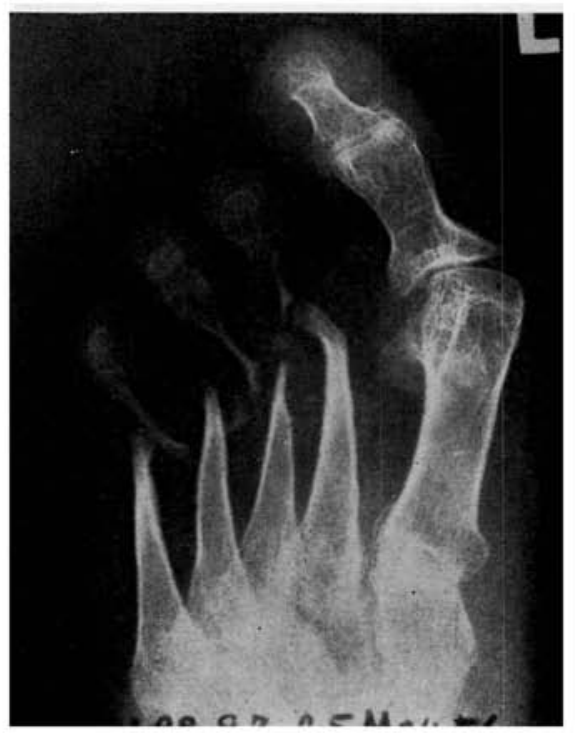

FIG. $13(b)$

Late result of chronic ulceration of the metatarsal head and severe concentric absorption of the adjoining bones. 


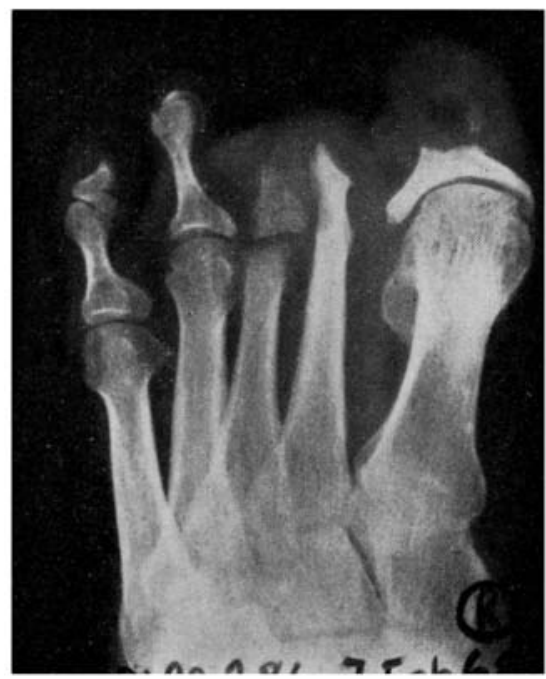

Fig. $14(a)$

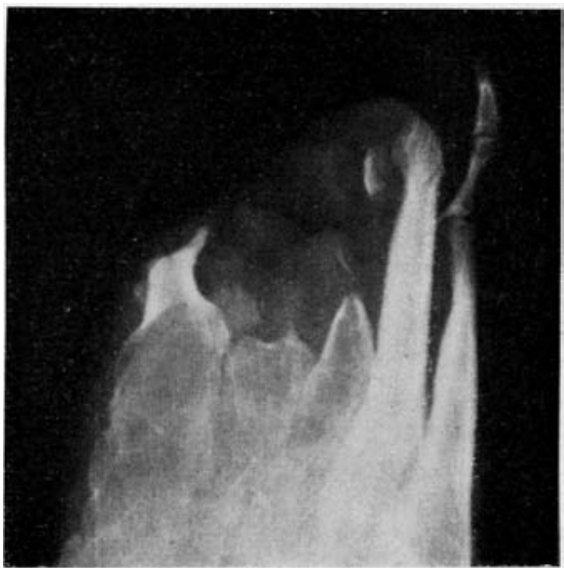

FIG. $14(c)$

FIG. $14(\boldsymbol{a})$ to $(d)$

FOREFOOT

$\mathrm{X}$-rays of a foot from 4 different patients demonstrate a pattern of progressive destruction and gross shortening of the forefoot. Scattered areas of destruction in the foref oot due to multiple areas of trophic ulcerations progressing to destruction and shortening of the entire forefoot. Finally, only the tarsals are left for weightbearing. These changes are most commonly associated with an uncorrected foot-drop of long duration. In a shortened foot, the present of foot-drop may not be appreciated by the casual observer.

FIG. $14(a)$

$\mathrm{X}$-ray shows that all the metatarsals are full length. The second metatarsal head is fused to the base of the proximal phalanx. The great toe sesamoids appear to

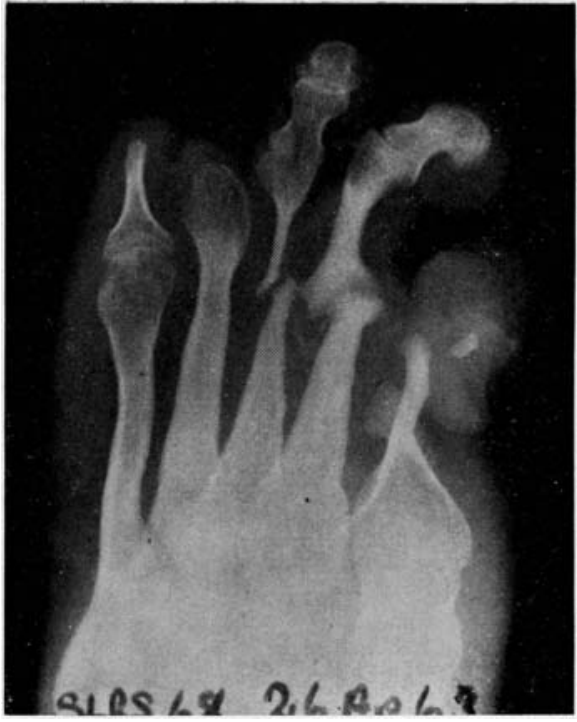

FIG. $14(b)$

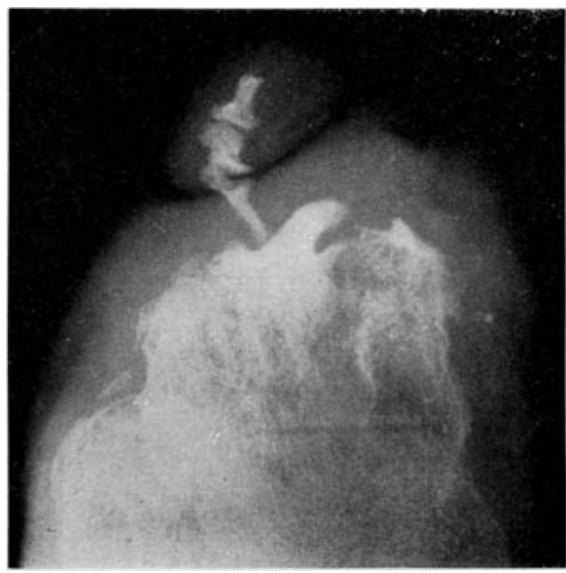

FIG. $14(d)$

be fusing with the head of the first metatarsal. The great toe metatarso-phalangeal joint is narrowed, with gross changes in the remnant of the proximal phalanx.

FIG. $14(b)$

First, second and third metatarsals show varying degrees of shortening and concentric absorption. There is progressive shortening of the forefoot.

FIG. $14(c)$

Severe shortening of the forefoot. Only the fourth metatarsal is nearly full length.

FIG. $14(d)$

Complete destruction of forefoot. Remaining toe is probably fourth. Remaining bones are mid-foot tarsals and fused remnants of bases of metatarsals. 


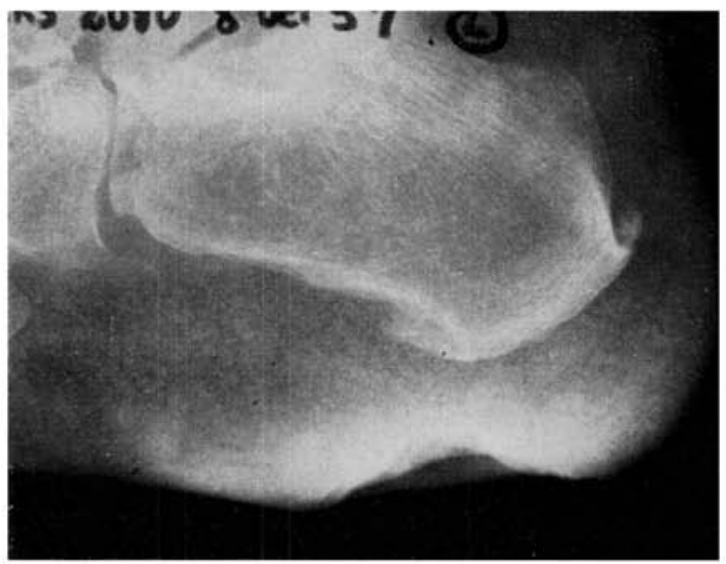

FIG. $15(a)$

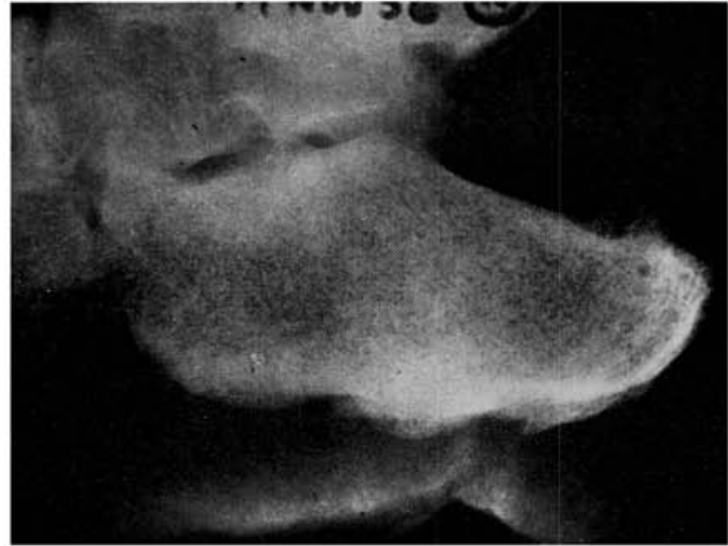

FIG. $15(b)$

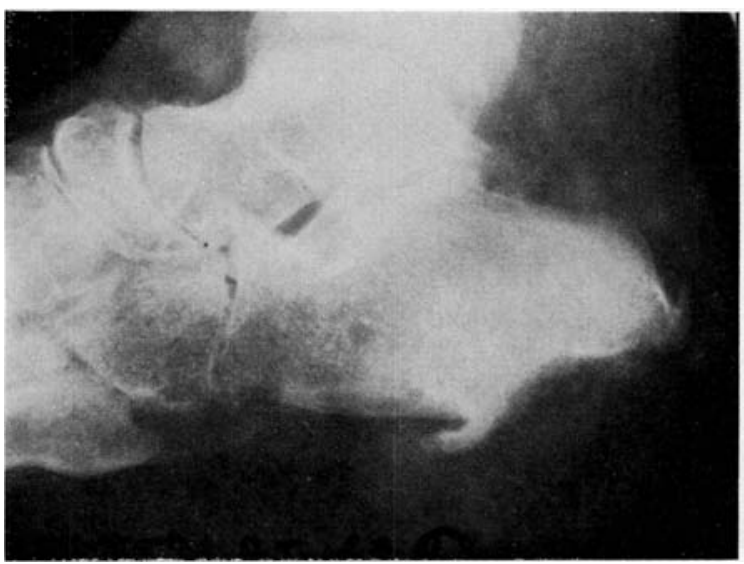

FIG. $15(c)$

FIG. $15(a)$ to $(c)$

Demonstrates destruction of the calcaneum caused by progressive hind-foot ulcer.

FIG. $15(a)$

Showing calcaneal ulcer under the tuberosity (inferior) of the calcaneum, with mainly soft tissue destruction.

Fig. $15(b)$

Showing soft tissue destruction and scarring leading to the bone, with extensive destruction of the inferior surface of the calcaneum and loss of a quarter of the height of the calcaneum.

\section{FIG. $15(c)$}

Showing destruction of the posterior-inferior part of the calcaneum, with involvement of the adjacent bone-sclerosis and loss of trabecular pattern. 


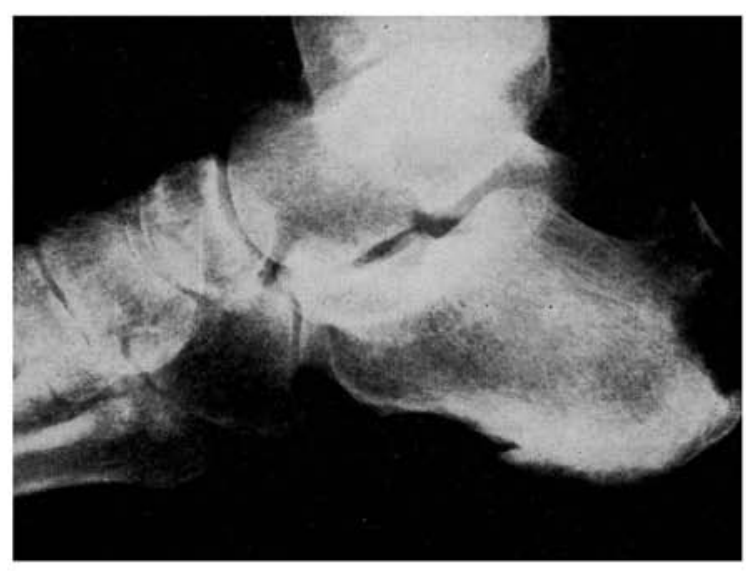

FI(x. $16(a)$

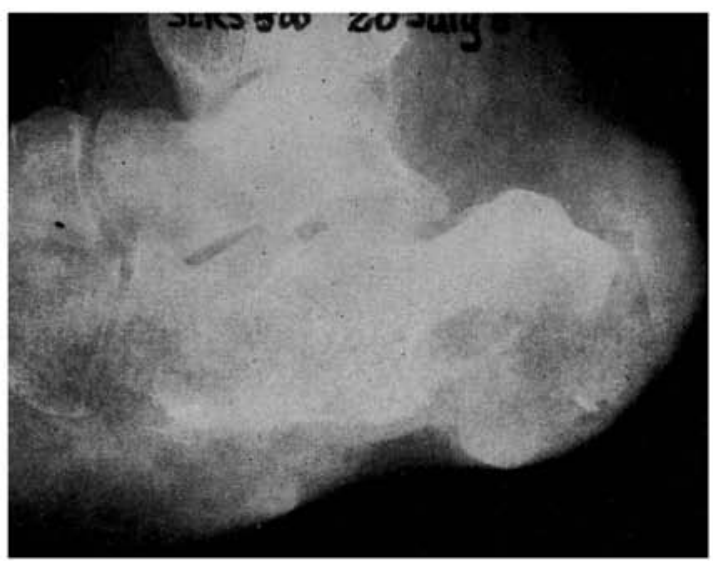

FIG. I6 (b)

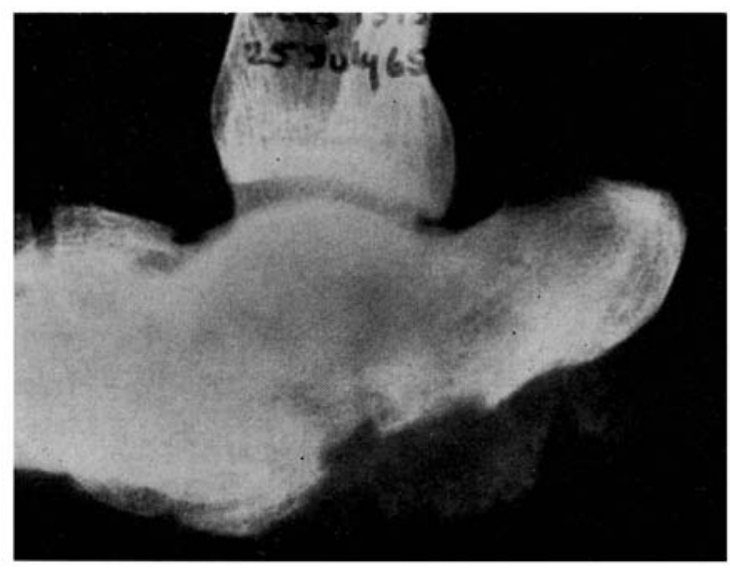

FIG. $16(c)$

Fig. $16(a)$ to $(c)$

Complications of Hind-Foot Ulceration

FIG. $16(a)$

Showing avulsion of the posterior tubercle at the tendo achillis' insertion following chronic calcaneal ulcer.

$$
\text { FIG. } 16(b)
$$

Showing gross destruction of the sof t tissues with deep involvement of the calcaneum, extending almost to its superior cortex. Pathological fracture, now healed, producing equinus deformity of the posterior half of the calcaneum, resulting in a lengthened and abnormally shaped calcaneum. Note the ulcer extending up to the bone, with very little soft tissue intervening.

$$
\text { FIG. } 16(c)
$$

Showing mid-foot collapse due to an anterior calcaneal ulcer destroying the short spring ligament, sustentaculum tali and other supporting structures for the head of the talus between the calcaneum and the navicular. The calcaneum is displaced posteriorly and upwards and the unsupported head of the talus tilts downwards towards the ulcer. Part of the talocalcaneal joint is destroyed. 


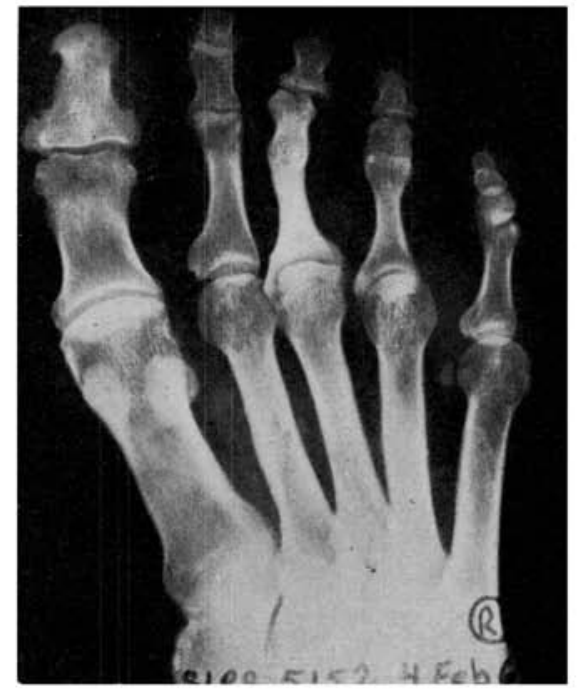

FIG. $17(a)$

FIG. $17(a)$ to $(c)$

Demonstrates need for maintaining the architectural balance in anaesthetic feet. Removal of even a small part of an essential component of the architecture of the foot results in the production of new areas of stress and pressure. These become vulnerable to ulceration, which results in a gross pattern of deformity.

Case History: Name: R.N. Age: 30. Sex: Male. SLRS No. 5152. Tuberculoid leprosy, with anaesthetic foot; presented during April, 1961, with deep fissure under right third toe. Duration: 2 months. Healed after plaster of Paris immobilisation. Third toe was clawed.

\section{FIG. $17(a)$}

February, 1963, again presented with an ulcer under the third toe. Foot immobilised in a plaster slab and later in a plaster of Paris walking cast. Ulcer healed and patient discharged. X-ray taken on 4.II.1963 shows sclerosis of the proximal phalanx and involvement of proximal interphalangeal joint of the right third toe. Patient presented again with an acute episode of swelling and infection of the third toe with purulent discharge. Bare bone felt through a sinus. Sloughed tendon was visible. One week later, sequestrectomy was performed, the proximal phalanx and most of middle phalanx being removed. Ulcer healed and patient discharged.

\section{FIG. $17(b)$}

Patient was admitted with a large gangrenous ulcer on the medial side of right fore-foot. The remnant of the third toe was a shrunken, flail appendage withdrawn proximally and displaced dorsally. The second and great toes had fallen into the gap left by the third toe, which resulted in marked valgus deformity. Patient wore a sandal with tight broad straps which pressed on the medial surface of the metatarso-phalangeal joint of the hallux valgus, which gave rise to a large area of necrosis. Soon the gangrenous area separated, exposing large areas of the underlying bones. X-ray taken on 14.IV.1966 shows valgus deformity of great and second toes, with large area of dead bone on either side of the metatarso-phalangeal joint of the great toe. The ulcer took 3 months to heal in a posterior slab, during which time most of the fragments of dead bone were extruded.

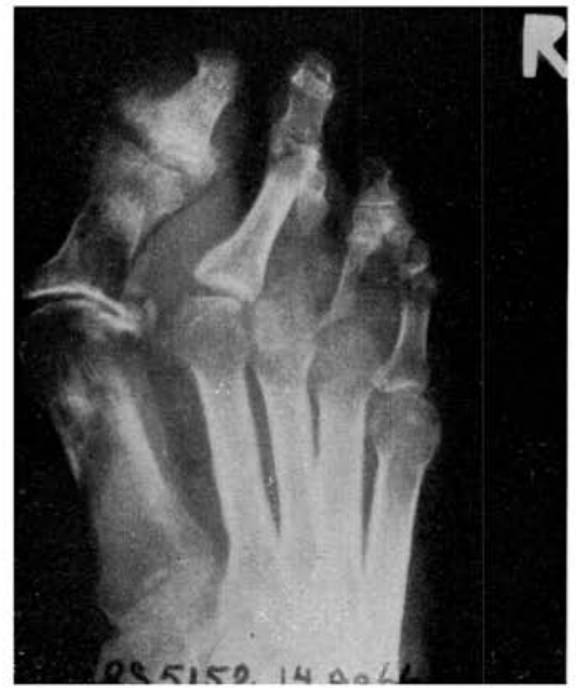

FIG. $17(b)$

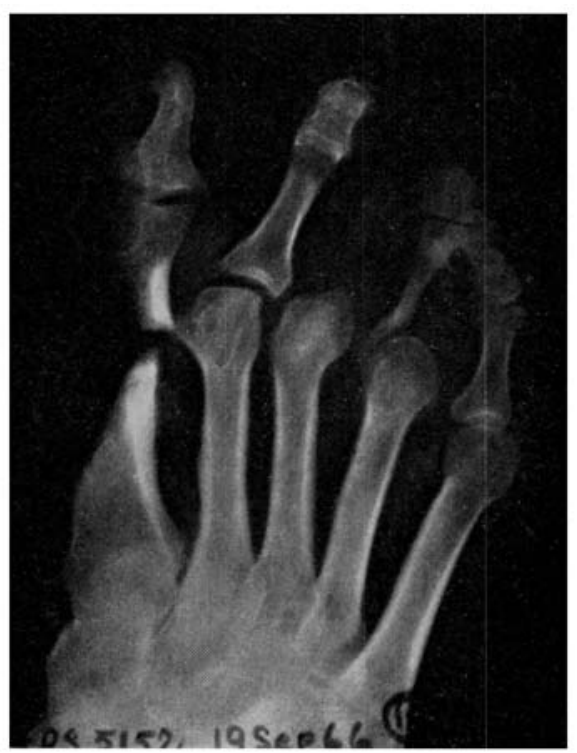

FIG. $17(c)$

Fig. $17(c)$

$\mathrm{X}$-ray of the same patient taken 19.IV.1966 shows total loss of adjoining surface of the first metatarsophalangeal joint, resulting in the loss of large area of weight-bearing surface of the medial ray of the foot. The middle of the proximal phalanx now lies at the level of the neck of the second metatarsal. It is difficult to believe that the gross deformity of the foot is a consequence of the loss of proximal part of the third toe. 


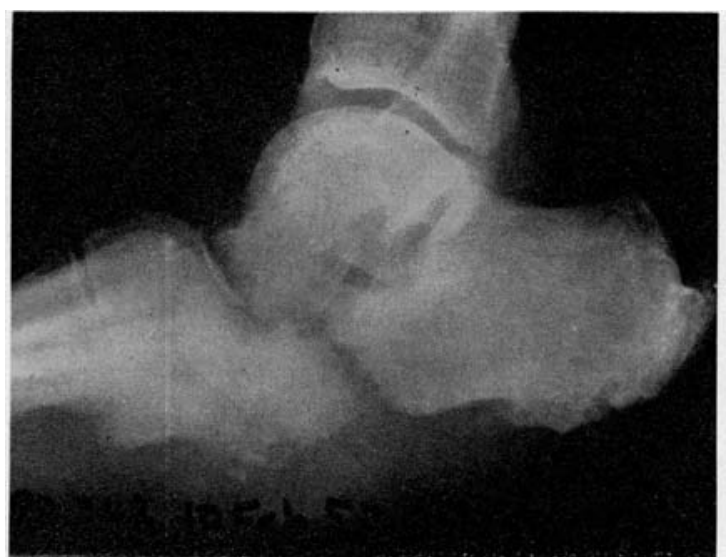

FIG. $18(a)$

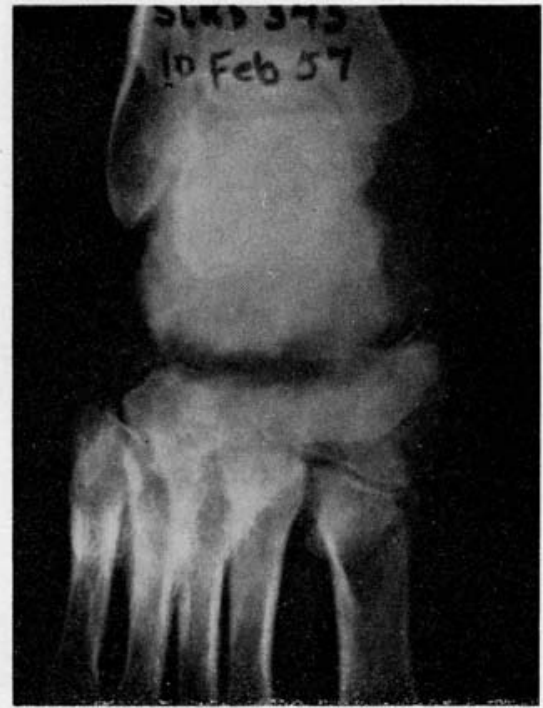

FIG. $18(b)$
Fig. $18(a)$ to $(c)$

Progressive destruction of the mid-foot, due chiefly to loss of soft tissue support, which assists the maintenance of mid-foot architecture.

Case History: Name: R. Age: 45. Sex: Male. SLRS No. 343. Tuberculoid leprosy of 10 years' duration, beginning with numbness of left heel. Early in the course of the disease, an ulcer developed on the left heel, which became chronic. The ulcer became chronically infected, and the infection eventually destroyed the mid-foot bony arch and left the foot clinically unstable.

$$
\text { Fig. } 18(a) \text { and }(b)
$$

Shows a heel ulcer which had extended forward to involve calcaneo-cuboid and calcaneo-navicular joints, with the loss of the short spring ligament. The sustentaculum tali of the calcaneum is detached from the forefoot and ceases to support the head of talus. The head of talus is pushed downwards into the gap, because of the transmission of the body weight through this line of force. The calcaneum, having lost its anterior attachments, is pulled backwards and upwards by the unopposed action of the tendo achillis. The medial arch of the foot is reversed, and the mid-foot becomes the maximum weight-bearing area. The boat-shaped foot renders the tarsals vulnerable to 'trophic' ulceration.

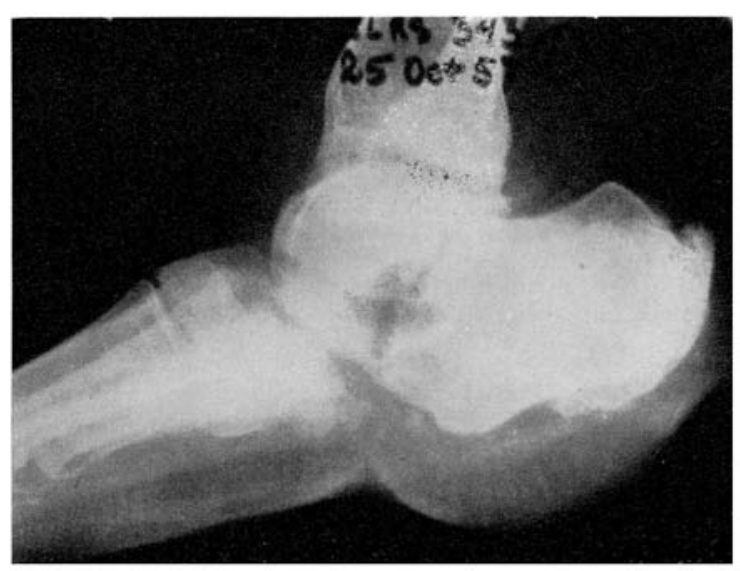

FIG. $18(c)$

X-ray taken 25.X.1957, shows loss of the head of the talus, navicular and most of cuboid, due to 'trophic' ulceration at the mid-foot. Calcaneum shows equinus deformity. The soft tissue shadow shows deformity of the contour of the sole. 


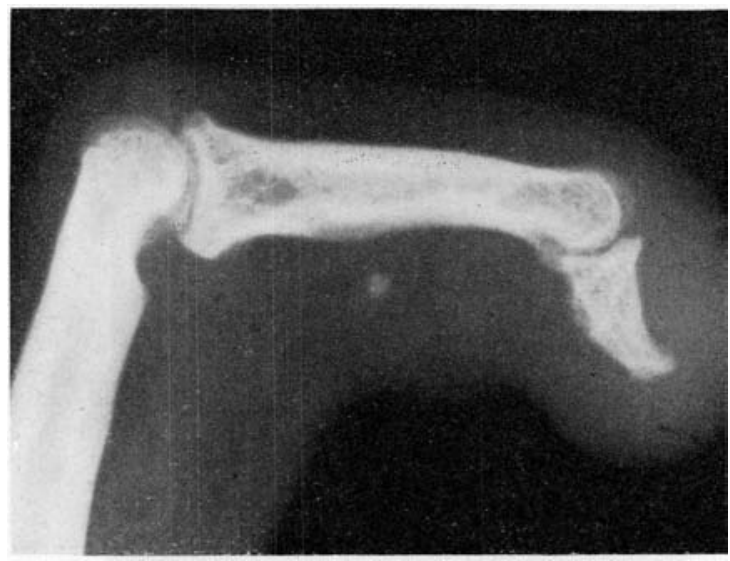

FIG. 19

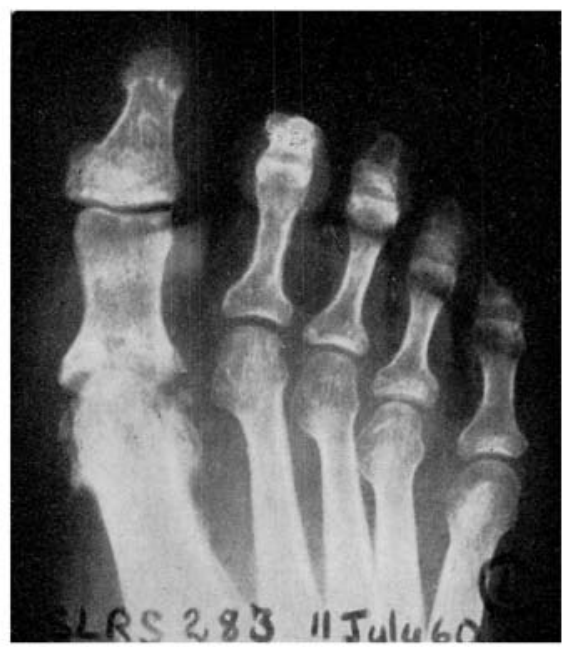

FIG. $20(a)$

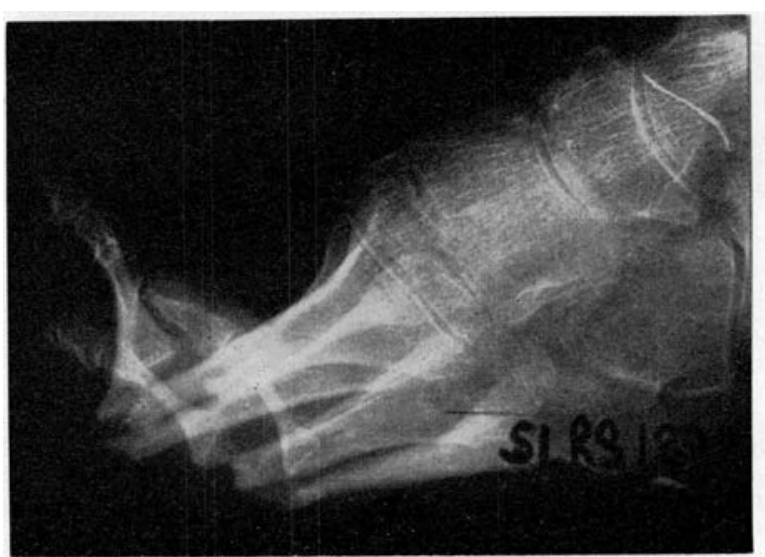

FIG. $20(c)$
Fig. 19

Case of ulnar paralysis resulting from nerve destruction above the elbow, resulting in a long period of clawing, with contracture of sof tissue and some capsular contracture of the anterior part of the proximal inter-phalangeal joint. X-ray shows early subluxation of the base of the middle phalanx with 'ditching' of the anterior surface of the neck of the proximal phalanx due to pressure atrophy from the contiguous surface of the base of the middle phalanx.

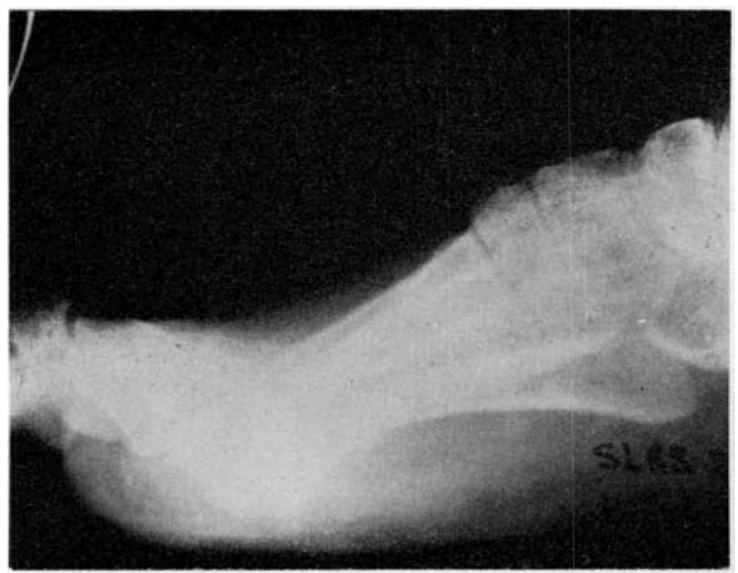

FIG. $20(b)$

Fig. $20(a)$ to $(c)$

Anaesthetic feet with posterior tibial nerve paralysis and early clawing.

FIG. 20 (a) and (b)

Antero-posterior and lateral view of a foot (SLRS No. 283) shows clawing of toes with hyperextension and dorsal subluxation of the proximal phalanges. Note sof t tissue shadow of 'trophic' ulceration under the first metatarsal head with early bone changes on the inferior surface of the first metatarsal heard in the lateral view. Antero-posterior view show X-ray changes of the adjacent sides of the first metatarsophalangeal joint with some early destruction and fragmentation of the articular surface of these 2 bones.

$$
\text { F'IG. } 20(c)
$$

Late result of 'trophic' ulceration over the metatarsal heads with posterior tibial nerve paralysis and claw toes. X-ray shows complete destruction of all the metatarsal heads with dorsiflexion and subluxation of the proximal phalanges of all the claw toes. The neck of the metatarsals is now the most prominent weightbearing surface. 


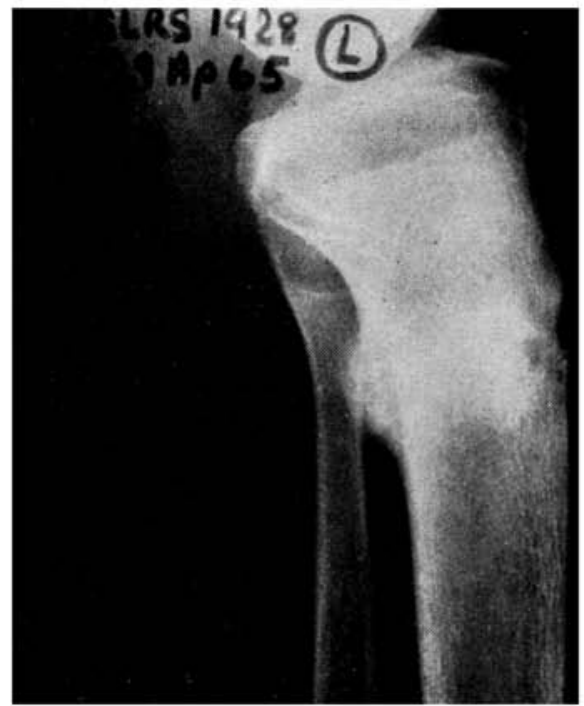

FIG. $21(a)$

Fig. $21(a)$ and $(b)$

Case History: Name: B. Age: 21. Sex: Male. H. No. 1928. Dimorphous leprosy, with chronic deep calcaneal ulceration of the left foot and complete loss of soft tissue under the calcaneum following accidental burn. Had 4 months' strict bed rest, followed by cross-leg flap for the heel, for which both legs were completely immobilised in a plaster cast for 3 weeks. Patient had

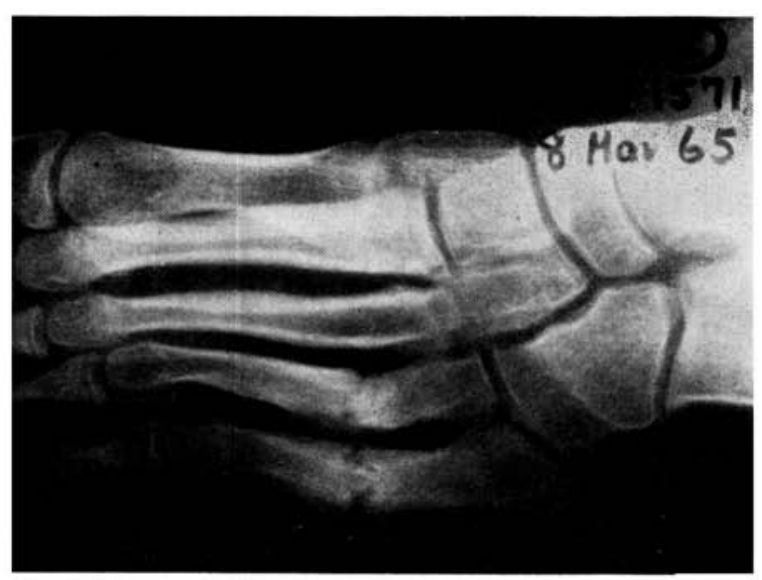

FIG. 22

Fracture Metatarsal

Case History: Name: K. Age: 18. Sex: Male. H. No. 3908. X. No. 1571. Dimorphous leprosy, with negative skin smears. Disease complicated by peripheral neuritis, treated with long-term steroids. Left foot-drop was partially supported with an above-ankle boot. Patient gives no history of a fall, injury, swelling or discomfort at any time during the past one year. $\mathrm{X}$-ray: Routine pre-operative $\mathrm{X}$-ray 8.III.1965, prior to tibialis posterior transfer, showed old healing fractures of fourth and fifth metatarsals. Previous $\mathrm{X}$-ray taken 11 months earlier shows no evidence of fractures.

\section{Leprosy Review}

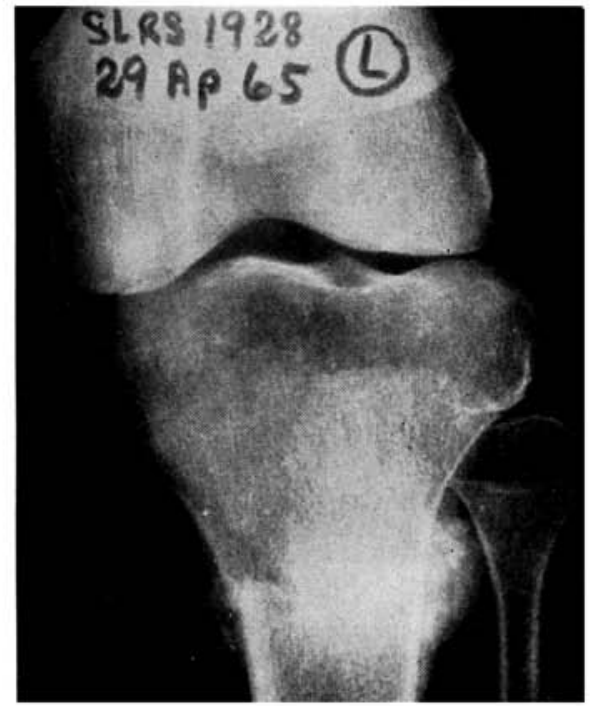

FIG. $21(b)$

a further period of $i$ weeks' rest before being allowed to walk. Had a total of 6 months of bed rest and/or immobilisation. On starting ambulatory treatment, patient complained of insidious onset of pain at the upper end of tibia; after the first 7 days, X-ray showed typical picture of march fracture with periosteal reaction in a fairly osteoporotic bone.

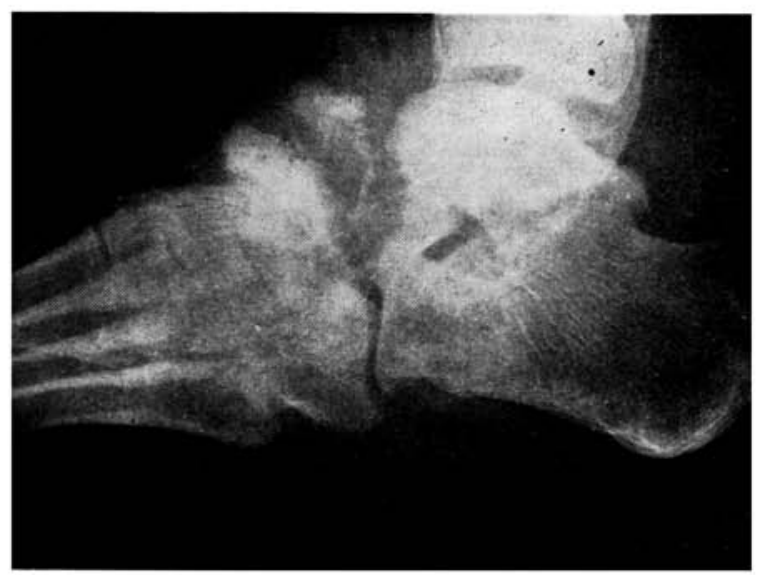

FIG. 23

Case History: Name: M. Age: 36. Sex: Male. H. No. 2544. X. No. 311 . Lepromatous leprosy. Negative skin smear 6.I.1959. History of lef t foot-drop with plantar ulceration, for which he was treated by repeated plaster immobilisation. Had tibialis posterior transfer on 30.III.1959. The foot was immobilised in maximum dorsiflexion post-operatively. Patient walked on this dorsiflexed plaster and complained of severe pain, following which plaster was removed. This X-ray taken 7 months later, shows fracture proximal neck of talus followed by avascular necrosis and destruction of the body of the talus. 


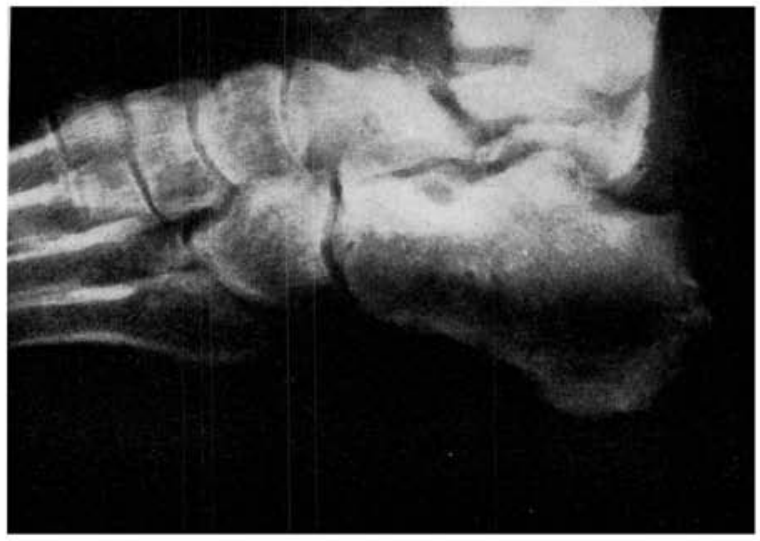

FIC. $24(a)$

FIs. $24(a)$ and $(b)$

Case History: Name: P. Age: 22. Sex: Male. H. No. 2028. Admitted on 2.VIII.1957 with bilateral foot-drop and anaesthesia of lower extremities. Was treated by repeated plaster immobilisation for plantar ulceration, followed by tibialis posterior transfer and immobilisation of the foot in maximum dorsiflexion. Postoperatively, patient complained of marked swelling and some discomfort of the left foot after walking on dorsiflexed walking cast.

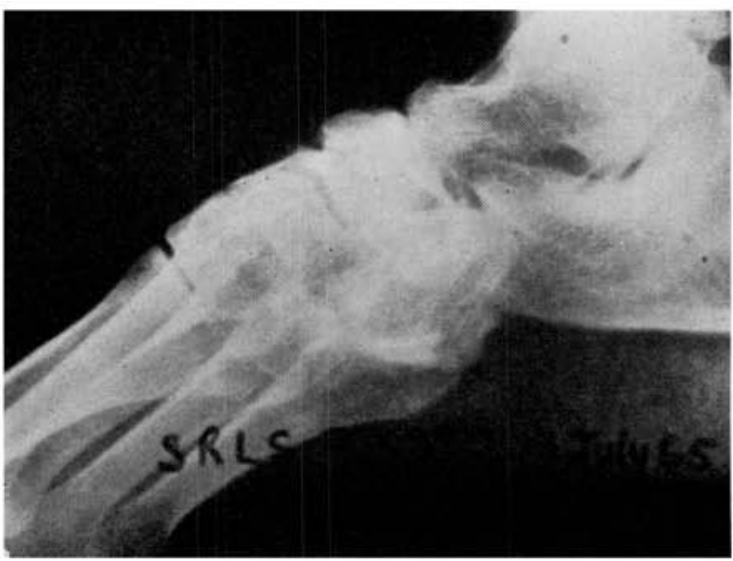

FIG. 25

Case History: Name: R. Age: 26. Sex: Male. No. 5898. Dimorphous leprosy (with negative skin smears), bilateral anaesthetic feet. Patient had foot-drop, for which tibialis posterior transfer was performed, giving a good result. Had a period of post-operative immobilisation, and a later period because of ulceration of the tip of the second toe. Subsequently he had a a minor twist and fall, following which he complained of slight discomfort on walking long distances.

On examination: There was localised warmth and slight swelling over the talo-navicular area, which subsided on complete bed rest in a posterior slab over a period of 48 hours. Though initial $\mathrm{X}$-rays did not reveal the fracture, it was clinically assumed to exist, and treated with a non-weight-bearing ischeal-bearing caliper.

$\mathrm{X}$-ray shows crack fracture across the navicular. This $\mathrm{X}$-ray, which was taken 7 months after the occurrence of fracture, shows the fracture line still present with no evidence of healing. Subsequently, the patient was allowed to weight-bear for a period of 4 weeks, after

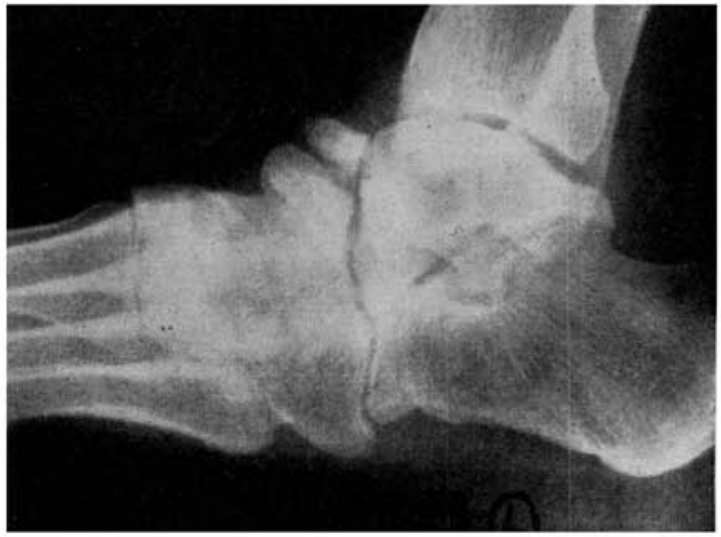

FIG. $24(b)$

X-ray: X-ray shows destruction of the head of the talus and navicular. Treated by immobilisation for a period of 6 months, following which the adjoining parts of the bone showed healing. Patient later had an abnormal flail sub-talar joint which needed arthrodesis. Summary: Fracture neck of talus and crush fracture of navicular, due to repetitive micro-traumata acting on osteoporotic bones: i.e., walking on an abnormally postured foot.

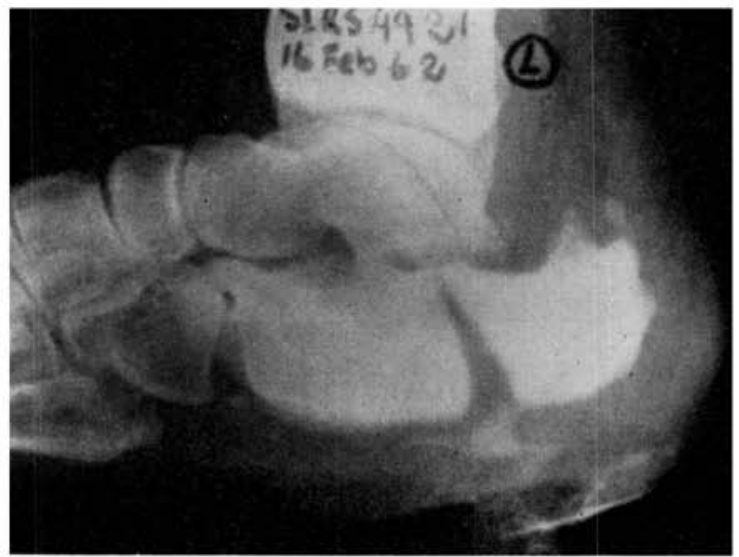

FIC. 26

which the navicular collapsed into half its width (not shown).

FIG. 26

Case History: Name: A.K. Age: 30. Sex: Female. H. No. 4921. Arrested lepromatous leprosy, with negative skin smears. Patient was treated for a chronic heel ulceration for $1 \frac{1}{2}$ years with repeated plaster of Paris immobilisation. Admitted on 26.I.1962 with an ulcer on the heel $1 \mathrm{~cm} . \times 1 \mathrm{~cm}$. with gross swelling, and redness of few days' duration. No history of trauma. $\mathrm{X}$-ray shows a fracture across the calcaneum The calcaneum is sclerosed and shows loss of normal trabecular pattern. The posterior half of the calcaneum is pulled upwards by the tendo achillis. The site of insertion of the tendo achillis is already deformed. A loose sequestrum lies inferiorly in the soft tissue. There is also evidence of underlying soft tissue involvement, due to 'trophic' ulceration.

Summary: Pathological fracture of the calcaneum in an ulcerated anaesthetic foot. The patient was un . aware of the fracture. 